\title{
Do Online Reviews Still Matter Post-Purchase?
}

\begin{abstract}
Purpose - The influence of eWOM information, such as online reviews, on consumers' decision making is well documented, but it is unclear if online reviews still matter in postpurchase evaluation and behaviours. We therefore examine the extent to which online reviews (aggregate rating and individual reviews) influence consumers' evaluation and post-purchase behaviour by considering the valence congruence of online reviews and consumption experience.
\end{abstract}

Design/methodology/approach - Following social comparison theory and relevant literature, we conduct an online experiment (pre-test: $n=180$; main study: $n=347$ ). We rely on a 2 (consumption experience valence) $\times 2$ (aggregated rating valence) $\times 2$ (individual review valence) between-subjects design.

Findings - Congruence/incongruence between the valences of consumption experience, aggregated rating and individual reviews affects consumers' post-purchase evaluation at the emotional, brand and media levels, and review-writing behaviour. In comparison to aggregated rating, individual reviews are more important in the post-purchase stage. Similarly, consumers have a higher eWOM-writing intention when there is congruence between the valences of consumption experience, aggregated rating and individual reviews.

Practical implications - We demonstrate the importance of service providers continually monitoring their business profiles on review sites to ensure consistency of review information, as these influence consumers' post-purchase evaluation and behaviours. For this reason, we illustrate the utility of why media owners of review sites should support the monitoring process to facilitate the engagement of both businesses and customers.

Originality/value - We break new ground by empirically testing the impact of online review information post-purchase seen through the theoretical lens of social comparison. Our approach 
is novel in breaking down and testing the dimensions of post-purchase evaluation and behavioural intentions in understanding the social comparison elicited by online reviews in the post-purchase phase.

Key words: Electronic word-of-mouth (eWOM), Online reviews, Post-purchase evaluation, Social comparison, Polarisation effects

Paper type: Research paper

\section{Introduction}

For over half a century, practitioners and academic literature alike have established word-ofmouth (WOM) as a direct determinant of consumption behaviour. With the advent of electronic platforms, electronic WOM (eWOM) has revolutionised consumers' decision-making processes (Hennig-Thurau et al., 2004). In practice, eWOM frequently refers to online reviews (Filieri and McLeay, 2014; Sotiriadis and Van Zyl, 2013). Previous studies have demonstrated that online reviews are important to consumers' purchase decision making, especially for services (e.g. hotels and restaurants) (Tsao et al., 2015; Yen and Tang, 2015). In this context, two types of eWOM are usually distinguished: base rate information (i.e. aggregated rating AR) and individuating information (i.e. individual reviews - IR), which in combination form a persuasive online environment, and are often jointly provided on review platforms (LópezLópez and Parra, 2016; Qiu et al., 2012). Aggregated rating refers to the rating that reflects former consumers' overall evaluation of a service provider, while individual reviews usually include the rating that a single consumer gives to a service provider, aligned with descriptive texts and, sometimes, images. These two types of eWOM information in the context of review sites are thought to influence both consumers' decision making and business growth (Luca, 2011; Xun and Guo, 2017).

eWOM researchers recognise the significance of understanding how different types of eWOM information, specifically AR and IR, on review sites, and the valence congruence/incongruence between them, influence consumer perception and behaviour at different stages of the decisionmaking process, particularly in service settings (Aggarwal and Singh, 2013; Chen et al., 2015; 
Qiu et al., 2012). However, the investigation of such effects has largely focused on the prepurchase stage, leaving the influence of online reviews on the post-purchase period underexplored (López-López and Parra, 2016; Qiu et al., 2012). This is surprising since, due to the ever-popular eWOM media and smart devices, consumers now have opportunities to access and receive an abundant amount of eWOM information across different media at any stage of the decision-making process, including the post-purchase evaluation stage. More importantly, the influence of online reviews post-purchase can be expected to significantly differ from the pre-purchase stage, not least due to the consumption experience customers have formed (Hess and Ring, 2016; Ranaweera and Jayawardhena, 2014). Based on Kardes (1994), Figure 1 conceptualises the eWOM information involvement in the consumers' decision-making process from an information-receiving perspective and clarifies the positioning of the current study, i.e. addressing the literature gap on consumer reactions towards online reviews postpurchase.

<Insert Figure 1 here>

More precisely, unlike the pre-purchase stage where consumers have limited knowledge and experience about the product/service, consumers have acquired their own consumption experience by the time they encounter online reviews in the post-purchase stage (Carù and Cova, 2003); thus, making the online review reception post-purchase fundamentally different from pre-purchase stages. The involvement of personal consumption experiences creates new dynamics in post-purchase evaluation, together with online review information received (Hess and Ring, 2016). Such new dynamics allow consumers to compare their own experiences with eWOM information on the review sites in which others' experiences with the same company are being shared. Such comparisons might confirm their own beliefs of the consumption experience in the post-purchase phase, or they might trigger the consumers' re-evaluation of multiple aspects related to the consumption (Bearden and Rose, 1990; Dahl, 2013; Smeesters et al., 2009). This unique phenomenon reflects the consumers' social comparison (Liu and Keng, 2014). Social comparison theory asserts that individuals constantly confirm their understanding and perceptions with those of other people (Festinger, 1954). Nevertheless, the social comparison drawn from the interaction between personal experience and online reviews in the post-purchase stage has not been fully examined in the literature. More specifically, 
compared to vertical social comparison (i.e. better vs. worse), horizontal social comparison (i.e. similar vs. different) is often neglected (Locke, 2003; 2005). This calls for an understanding of the impact of horizontal social comparison on consumers' post-purchase evaluations.

With regard to the potential outcomes of social comparisons elicited by eWOM information post-purchase, the literature suggests that consumers not only form cognitive and emotional evaluations towards a product/service at this stage, but also adjust their brand perception (Bigne et al., 2001; Grace and O'Cass, 2004; Kuo et al., 2009). Meanwhile, consumers can also reevaluate the eWOM platform's credibility based on consistence between the information available on the site and their personal experience (Hood et al., 2015). This creates a mediarelated dimension in consumers' post-purchase evaluation in the specific context of eWOM. Therefore, assessing interactions between consumption experience and online reviews requires in-depth understanding of consumers' post-purchase evaluation as a multidimensional concept. Additionally, the literature suggests that consumers' post-purchase evaluation also has a significant impact on eWOM-giving behaviour (Jeong and Jang, 2011; Yu et al., 2017). eWOM-giving is media-specific; on review sites it is reflected in consumers' online review writing post-purchase (Yen and Tang, 2015). Therefore, a multidimensional evaluation might influence consumers' eWOM-giving behaviour. Recent service research also recognises that social comparison has a strong impact on consumers' post-purchase evaluation and eWOM behaviour (Allen et al., 2015; Antonetti et al., 2018). Therefore, it is important to explore the dimensionality of post-purchase evaluation triggered by social comparison of the congruence/incongruence between personal experience and eWOM information, and to examine its impact on consumers' eWOM-giving behaviour.

This study therefore contributes to the existing literature on eWOM and consumers' postpurchase evaluations in several ways. First, we push the boundaries of pre-purchase-centred eWOM information studies by uniquely focusing on the eWOM information received in the post-purchase stage and its impact on consumers' evaluations and eWOM-giving behaviour. Second, we employ often-neglected horizontal social comparison instead of vertical comparison and shed new light on the role of social comparison in consumers' post-purchase evaluations. Third, we reconceptualise the post-purchase evaluation as a multidimensional concept and categorise post-purchase evaluation into consumption-related and media-related dimensions, thereby advancing the theoretical understanding of social comparison-triggered post-purchase evaluations. 
Thus, drawing upon social comparison theory, we specifically examine the interactive effects of aggregated rating (AR), individual reviews (IR) and consumption experience (CE) on postpurchase evaluation and eWOM-giving behaviour on the review site. We present background information on the constructs under examination, before formulating our hypotheses. The research methodology is then detailed. After presenting the data analysis and results, the paper concludes with a discussion of the study's outcomes and its implications for theory and practice, the limitations of the study, and future research directions.

\section{Literature Review}

In an information age, consumers have opportunities to access different types of information across various media. On the review sites, valence is an important indicator of eWOM information that influences consumers' judgement (Purnawirawan et al., 2015). While different types of eWOM information on review sites (e.g. AR and IR) could reflect different valences (positive vs. negative), one research stream in online reviews has been dedicated to understanding the impact of valence congruence/incongruence of eWOM information on consumers' perceptions (e.g. López-López and Parra, 2016; Qiu et al., 2012). Table 1 summarises previous studies that focus on the valence congruence/incongruence between multiple eWOM cues.

<Insert Table 1 here>

All these studies emphasise the pre-purchase stage and employ theories related to information processing and risk reduction to explain consumers' evaluation of the related product/service and eWOM information when facing information valence congruence/incongruence. Most emphasise the conflict between AR and IR as they are the most essential eWOM elements on review sites. Since these studies focus on the pre-purchase stage in which consumers are assumed to have no or limited knowledge and experience with the product/service, the evaluations of the product/service rely entirely on the eWOM information and its valence congruence/incongruence. However, in the post-purchase stage where the consumer has gained personal experience with a product/service, when different types of eWOM information about the same product/service are present, the post-purchase evaluation no longer depends only on 
the valence congruence/incongruence of eWOM information but also involves the valence of the personal experience and its congruence/incongruence with the eWOM information. In consumer research, consumption experience usually refers to "the total outcome to the customer from the combination of environment, goods, and services purchased" (Lewis and Chambers, 2000, p. 46) and can be seen as a valence-based construct which has a major influence on post-purchase evaluation (Mano and Oliver, 1993). Hence, we advance the previous eWOM studies' focus on the valence congruence/incongruence by taking the valence of personal experience into account and examining the interactive effects of valence congruence/incongruence post-purchase. More specifically, when consumers encounter online reviews post-purchase, the influence is bi-directional. More precisely, they can a) use such information to compare with and evaluate their personal consumption experience, or b) use their personal consumption experience as a benchmark to evaluate the online reviews and the medium. In such comparison, the outcome could depend on the valence congruence/incongruence between the consumers' personal experience and eWOM information provided by other consumers. The interaction of consumption experience and received eWOM information post-purchase results in self-others comparison in terms of the consumption of the same product/service (Andsager and White, 2007). This phenomenon can be explained by using social comparison theory. Figure 2 illustrates the contextualisation of the social comparison in this study.

$<$ Insert Figure 2 here $>$

\subsection{Social Comparison Theory}

\subsubsection{Horizontal Social Comparison}

Festinger's social comparison theory (1954) asserts that individuals evaluate their own opinions and abilities by comparing them with others'. This reduces uncertainty and helps individuals learn more about themselves. Richins (1995) argues that consumers continually desire to learn more about themselves, not least through comparison with others. Social comparison contains two dimensions: vertical (better-worse) and horizontal (similar-different) comparisons (Locke, 2005). Previous research claims that about half of social comparisons are vertical, that is whether the comparison target is better (an upward comparison) or worse (a downward comparison) than the self (e.g. John had a better experience than I did at Hotel A). 
The remaining comparisons are horizontal, focusing on whether the target is similar to (a connective comparison) or different from (a contrastive comparison) the self (e.g. Emma enjoyed her stay at Hotel A and so did I) (Locke, 2003). Most social comparison studies concentrate on the vertical approach and its impact but neglect horizontal comparisons. Importantly, the motivation for and outcome of the comparison vary between the vertical and the horizontal dimensions (Locke, 2005). Locke (2003, 2005) also asserts that when one compares oneself horizontally with the target (i.e. the person with whom the self compares) regarding the target attribute (i.e. the feature of the target that is being compared with a corresponding feature of the self), the self's beliefs, attitude, emotional status and cognitive evaluation towards the target attribute will be influenced. Meanwhile, social psychologists assert that when social comparison results in inconsistent beliefs concerning the target attribute, cognitive dissonance occurs (Festinger, 1962; Goethals, 1962). Cognitive dissonance refers to the mental discomfort experienced in holding contradictory beliefs, ideas or values; such contradictions could further shape one's beliefs about the target attribute (Festinger, 1962; Liu and Keng, 2014). In this study, the target is peer consumers, and the target attribute is the valence of the experience of peer consumers with the same service provider.

More precisely, building upon previous studies on valence congruence/incongruence of eWOM information (e.g. Qiu et al., 2012; see Table 1), we focus on social comparison that involves two different types of cue post-purchase: base-rating (i.e. aggregated rating; target: all consumers who visited and reviewed the service provider) and individuating (i.e. individual reviews; target: specific consumers who visited and reviewed the service provider). Both are valence-based (positive vs. negative), which offers unified comparison standards by which a consumer can assess whether his/her personal experience is similar to (same-valenced) or different from (differently-valenced) that of others at the specific and general levels (LópezLópez and Parra, 2016). As already explained, horizontal comparison triggers cognitive dissonance and has an impact on one's attitudinal, emotional and evaluative beliefs regarding the target attribute. Thus, the valence congruence/incongruence between consumer's personal consumption experience with a service provider and eWOM information reflecting others' experience with the same service provider is expected to influence consumers' evaluations and subsequent behaviours associated with the service provider. 


\subsubsection{Social Comparison on Digital Media}

It is argued that consumers utilise information from different media (Smeesters et al., 2009), as well as social capital sources (Argo et al., 2006), to evaluate themselves (Richins, 1991) and product/service information (Hogg et al., 2000). With the growing popularity of social media, consumers' social comparison has also been digitised (Haferkamp and Krämer, 2011). Vogel et al. (2015) suggest that social comparison is a key motivator for social media use. It also influences consumer engagement with brands and peer consumers on social networking sites (Phua et al., 2017). Therefore, social comparison in the online environment has become a major approach for consumers to conduct self-confirmation and evaluate products and services. Previous research also suggests that social comparison that takes place online affects individuals' evaluation of a particular site. For example, online social comparison can contribute to the perceived usefulness and enjoyment of a social shopping website (Shen, 2012), and Shang et al. (2013) argue that satisfaction with a virtual community is an outcome of the individuals' social comparison in that community. We therefore postulate that, in addition to the influence on comparing targets, online social comparison could also affect consumers' judgement regarding the media that facilitated the social comparison.

\subsubsection{Social Comparison in eWOM}

Although social comparison has not been used extensively in eWOM research, some pioneering scholars identified eWOM-triggered social comparison and its possible implications, especially in the post-purchase stage. eWOM received post-purchase allows consumers to reform their perception of the consumed product/service, thereby influencing switching behaviour (Wangenheim and Bayón, 2004). Further, Hess and Ring (2016) assert that the valence of WOM information about a service provider received in the post-failure stage affects consumers' satisfaction and trust towards that service provider. Additionally, eWOM information received in the post-purchase stage has been found to influence consumers' eWOM-giving behaviour (Liu and Keng, 2014), triggered by comparison as a social need of consumers (Alexandrov et al., 2013; Choi et al., 2017). Thus, in the post-consumption stage of a service, social comparison elicited by eWOM information is expected to influence consumers' evaluation of the service provider and further eWOM-giving.

Although researchers employing social comparison theory have suggested that eWOM information might trigger social comparison in the post-purchase phase, almost all focus on a single type of (e)WOM information. Compared to the studies in the pre-purchase stage (see 
Table 1), multiple information cues should be considered in eWOM-triggered social comparison. Therefore, drawing upon social comparison theory, this study recognises that the review site provides multiple cues for post-purchase comparison, which not only addresses the ambiguity of consumers' attitudes and perceptions towards a particular service, but also influences the consumers' own eWOM-giving. By specifically focusing on the effects of aggregated rating and individual reviews, we conceptualise horizontal social comparison as the fact that a consumer compares the valence of his/her personal experience with a service provider with the valence of other eWOM information at aggregated and individual levels on the review site in the post-purchase stage. These arguments rationalise the potential effects that online social comparison might have on service consumption-related evaluation, media-related evaluation and consumers' eWOM behaviour. We advance the following framework (Figure 3) to explain eWOM-triggered social comparison in the post-purchase stage.

$<$ Insert Figure 3 here>

\subsection{Dimensionality of Post-Purchase Evaluation}

Consumption experience elicits both cognitive and emotional evaluation in the post-purchase phase (Mano and Oliver, 1983). In service research, cognitive and emotional evaluation usually refers to perceived service quality and consumption emotion. Consumers also evaluate brands through their consumption experience which, in turn, affects the brand image of the service provider (Padgett and Allen, 1997). In addition to consumption-related evaluation, postpurchase eWOM information allows consumers to assess the credibility of eWOM media (Bachleda and Berrada-Fathi, 2016).

\subsubsection{Emotional Evaluation - Emotional Intensity}

Social sharing of emotion is an area peripheral to social comparison theory (Festinger, 1954; Rimé, 2009). It suggests that any emotion can be deconstructed into two dimensions: emotional valence (i.e. positive vs. negative) and emotional intensity (i.e. low vs. high) (Rimé, 2009). More precisely, emotional valence refers to the emotional evaluation of a particular event, object or situation, and emotional intensity measures the strength with which an emotion manifests itself (Catino and Patriotta, 2013). This dual-dimensionality of emotion also applies 
to consumption emotion (López-López et al., 2014). As the initial emotional response drawn from an event (i.e. consumption experience), emotional valence is relatively unchangeable; whereas emotional intensity can fluctuate over time depending on the intervention of information and interaction with others and can be seen as an indicator of individuals' emotional evaluation in the post-event phase (Rimé, 2009; Rimé et al., 1998). Thus, as a form of interventional information, aggregated rating and individual reviews are likely to influence consumers' emotional intensity and emotional evaluation in the post-purchase stage.

\subsubsection{Cognitive Evaluation - Perceived Service Quality}

As an important evaluative component in the post-purchase phase, perceived service quality measures the degree and direction of the discrepancies between a service receiver's expectations and perceptions (Grover et al., 1996; Parasuraman et al., 1988). Although early studies assumed that individual expectations are consistent and only relevant pre-consumption (e.g. Oliver, 1977), later research found that expectations change over time (Bhattacherjee and Premkumar, 2004). Expectations during and after consumption may differ from those formed before consumption, since consumers' expectations are shaped by differences between their own and others' experiences (Oliver and Burke, 1999). Hence, when consumers have the opportunity to compare their own experience with others (eWOM - AR and IR), their expectation could be changed. If there is incongruity in the self-others comparison, the self will establish new standards for evaluating the consumption experience (Stayman et al., 1992).

\subsubsection{Brand Evaluation - Brand Image}

In addition to emotional and cognitive evaluation, consumption experience and received eWOM can also influence brand image. Brand image refers to consumers' perceptions and encompasses the set of beliefs that consumers have about a brand, drawn from both personal experience and external information (Nandan, 2005). Both aggregated rating and individual reviews affect brand image, in that AR reflects a historical record of how the brand is viewed by former customers, and IR presents details about how former customers form brand perceptions (Cantallops and Salvi, 2014). eWOM among peer consumers has also been shown to influence brand image (Jalilvand and Samiei, 2012). At the same time, consumption experience also has a direct impact upon brand image (Chen et al., 2014; Padgett and Allen, 
1997). The interaction between consumption experience and received eWOM is, therefore, expected to elicit a re-evaluation of the image of the referred brand.

\subsubsection{Media Evaluation - Perceived Credibility of the Review Site}

Aggregated rating and individual reviews are known to affect how consumers perceive the credibility of review sites (Fogg et al., 2003). The perceived credibility of a medium generally refers to the message recipient's perception of the credibility of the medium on which the message is presented (Cheung et al., 2008; Gvili and Levy, 2016). Consumers' judgements of information credibility and media credibility are mutually influential (Metzger et al., 2003; Qiu et al., 2012). Therefore, in the post-purchase stage, consumption experience increases consumers' knowledge of the product/service and, as a result, affects the evaluation of the credibility of eWOM information and media (Cheung et al., 2009; Doh and Hwang, 2009).

\section{Hypotheses Development}

\subsection{Polarisation Effects in Post-Purchase Evaluation}

Polarisation effects are a social psychological phenomenon. They describe how an emotion and/or attitude becomes more extreme after exposure to, deliberation on, and/or communication about, emotionally and/or attitudinally congruent information (Chan and Cui, 2011; Lord et al., 1979; Petty and Krosnick, 2014). Internet-mediated communication fosters interactive and dynamic information exchange, and therefore accelerates the formation of polarisation effects (Parsell, 2008). Previous eWOM studies suggest a polarisation phenomenon in which consumers' disposition, attitude and purchase preferences could be biased by emotional and cognitive tendencies held prior to the effects of the polarisation (Chan and Cui, 2011; Hu et al., 2006; Park and Park, 2013). When consumers experience either positive or negative episodes, they may, through the lens of social comparison, compare the valence of their consumption experience with the eWOM valence, thereby examining congruence between self and others. Since polarisation effects are not valence-biased (Tesser and Conlee, 1975), eWOM information with the same valence (i.e. negative or positive) enables consumers to feel connected with others through consistent service perceptions and emotions. This evokes emotion and cognition polarisation, i.e. an increase in negative/positive evaluation. As described in the literature review, both consumption experience and eWOM information have an influence on the different dimensions of post-purchase evaluation. Thus, 
congruence between the valences of consumers' consumption experience and received eWOM appears to contribute to attitudinal, emotional and perceptual polarisation.

H1. Valence congruence between consumption experience, aggregated rating and individual reviews influences (a) emotional intensity, (b) perceived service quality, (c) brand image, and $(d)$ perceived credibility of the review site more than incongruence.

\subsection{Aggregated Rating vs. Individual Reviews}

Social comparison (consumption experience - received eWOM) influences consumers' postpurchase evaluation in four dimensions. Festinger (1954) suggests that congruence between a consumer's beliefs and the target has a strong impact on the construction of reality. Hence, congruence between the valence of a consumption experience, aggregated rating and individual reviews enables consumers to confirm their beliefs. However, when there is incongruence between the valence of aggregated rating and individual reviews, the weights of these two types of cue in developing consumers' judgement and evaluation tend to be different (Tsang and Predergast, 2009). Early research on social cognition suggests that individuals tend to emphasise individuating information over base-rate information in decision making when both are available, as individuating information often contains more cues that facilitate the individual's cognition (Borgida and Nisbett, 1977; Locksley et al., 1982; Nisbett and Borgida, 1975). Meanwhile, previous eWOM research shows that, compared to aggregated rating, argument-based eWOM (i.e. individual reviews) predominately influences consumers' evaluation of received eWOM information as it contains more informative and diagnostic cues (Chong et al., 2018; Filieri and McLeay, 2014; Ma et al., 2013). More specifically, Tsang and Predergast (2009) argue that when there are incongruent valences between aggregated rating and individual reviews, individual reviews have a stronger impact on consumers' decision making. Therefore, based on this empirical evidence, individual reviews outweigh aggregated rating in consumers' information-processing and evaluative-belief development. In the postpurchase stage, consumers tend to compare the valence of personal experience and the received eWOM information, thereby confirming their beliefs and re-evaluating their consumption experiences (Hess and Ring, 2016; Locke, 2005). When both aggregated rating and individual reviews are available, as the previous studies suggested, consumers are expected to place more emphasis on the congruence between personal experience and individual reviews to confirm and refine their evaluative beliefs. 
H2. Valence congruence between consumption experience and individual reviews (as opposed to valence congruence between consumption experience and aggregated rating) has a stronger influence on (a) emotional intensity, (b) perceived service quality, (c) brand image, and (d) the perceived credibility of the review site.

That both aggregated rating and individual reviews are important for pre-purchase decision making is widely recognised (Camilleri, 2017; Shen et al., 2018). However, we posit that aggregated rating is less important following a purchase (H2), although whether aggregated rating still matters at all remains unknown. Nonetheless, since aggregated rating and individual reviews are used to build the persuasive environment of review sites, aggregated rating should contribute to the evaluation of eWOM media credibility (Qiu et al., 2012). Consumptionrelated evaluation might be affected differently by aggregated rating post-purchase. As a historical record of how others regard a business/brand, aggregated rating might have limited impact on emotional intensity and perceived service quality, which generally originate from consumption experience (Cantallops and Salvi, 2014). However, consumers' perception and brand image include historical brand reputation and personal experience (So and King, 2010; $\mathrm{Xu}$ and Chan, 2010). In other words, consumers take both their own prior experience and how a brand has performed in the market into consideration when judging the image of a particular brand, whereas aggregated rating provides an intuitive indicator of how the brand is considered in the market. Consequently, we posit that AR has a stronger impact on brand image.

\section{H3. Aggregated rating has a stronger influence on brand image than emotional intensity and perceived service quality.}

\section{3 eWOM-giving Behaviour}

eWOM received post-purchase could also influence consumers' eWOM-giving behaviour (Alexandrov et al., 2013; Hess and Ring, 2016; Ranaweera and Jayawardhena, 2014). Review sites include an information pool, in which consumers' opinions gradually form major (congruent with most consumers') or minor (incongruent with most consumers') voices. Such congruence/incongruence between a consumer's personal opinion and public opinion could potentially determine how likely he/she is to offer an opinion. The spiral of silence (NoelleNeumann, 1991) was originally established in political science and mass communication and suggests that, as individuals fear being isolated, they tend to remain silent when their opinion differs from the dominant idea. Individuals are more likely to make their voice heard when 
their opinion is similar to that of the majority (Glynn et al., 1997). The effects of the spiral of silence were first identified in the offline environment but have also been observed in social media use across different platforms (Chen, 2018; Stoycheff, 2016; Gearhart and Zhang, 2015). Some pioneering studies support the effects of the spiral of silence in online reviews (Askay, 2015; Johnen et al., 2018; Pan et al., 2018; Zerback and Fawzi, 2017). For example, Askay (2015) shows that consumers tend to contribute to the dominant opinion in online review systems and avoid belonging to the minority. In the context of our study, when same-valenced aggregated rating and individual reviews form a majority voice, consumers who hold a congruent view are more likely to offer an opinion. In contrast, incongruence between a consumer's personal opinion and the public view isolates the consumer from the majority and constrains the consumer from giving a different opinion. Thus, comparison of a consumption experience with the eWOM information on review sites helps consumers to identify whether they belong to the majority or the minority, which could, in turn, influence eWOM-giving intentions.

H4a. Valence congruence between consumption experience and eWOM information (aggregated rating and individual reviews) leads to the highest eWOM-giving intention, compared to any other congruence/incongruence.

H4b. Valence incongruence between consumption experience and eWOM information (aggregated rating and individual reviews) leads to the lowest eWOM-giving intention compared to any other congruence/incongruence.

Post-purchase evaluations also affect eWOM-giving behaviour. Social sharing of emotion as the extension of social comparison theory with a particular emphasis on emotion, suggests that emotional intensity is a strong predictor of social sharing (Rimé et al., 1998). In the offline environment, according to social sharing of emotion effects, the more intense the emotion drawn from an event, the more frequently the event will be shared (Rimé et al., 1998; Rimé, 2009). A recent study also suggests a positive association between emotional intensity and eWOM-giving intention on different platforms (Liu and Jayawardhena, 2018). In the postevent stage, emotional intensity may change over time as information and interaction intervene, whereas residual emotional intensity still has a positive influence on the sharing of an experience (Rimé, 2009). Therefore, emotional intensity in the post-purchase phase is expected to affect consumers' eWOM-giving intention.

H5. Emotional intensity positively influences eWOM-giving intention. 
We postulate that positive consumption experience, combined with eWOM received, facilitates the formation of a positive brand image of the service provider. During social comparison, consumers who draw upon positive emotion and evaluation generate a sense of superiority, whereas the sense of superiority drawn from self-others comparison is expected to lead to motivational self-enhancement (Andsager and White, 2007; Xie and Johnson, 2015), which is a central driver of eWOM-giving when based on positive experience (Chawdhary and Dall'Olmo Riley, 2015; Islam et al., 2017). Similarly, appreciation of a premium service drawn from social comparison motivates consumers to express positive feelings and evokes the desire to help and support the service provider and its brand (Jeong and Jang, 2011; Kim and Lee, 2017). In the service setting, research suggests that consumers' perception of the service quality is a key evaluative indicator and is positively associated with consumers' WOM- and eWOMgiving (Ifie et al., 2018; Jun et al., 2017; Kim et al., 2015). Thus, when the perceived service quality is high, consumers are more likely to share positive eWOM (Cantallops and Salvi, 2014).

\section{H6. Brand image positively influences eWOM-giving intention.}

H7. Perceived service quality positively influences eWOM-giving intention.

With the ongoing evolution of online media, consumers have become increasingly selective when choosing media for active use and engagement (Kang, 2010). This effect has also been observed in eWOM media (Sotiriadis and Van Zyl, 2013). To maintain consumers' engagement, eWOM media have been striving to build a trustworthy online environment, allowing consumers to seek and share information with minimum concern, and establish a reputable media brand (Park and Lee, 2009). Previous studies have claimed that the perceived credibility of a review site contributes positively to consumers' engagement with that site and to the site's reputation (Chu and Kamal, 2008; Tsai and Men, 2013), whereas, in the postpurchase phase, consumers judge the credibility of a site based on self-others comparison. In this case, consumers' engagement with review sites could be reflected in eWOM-giving intention.

H8. Perceived credibility of a review site positively influences eWOM-giving intention. 


\section{Methodology}

\subsection{Experimental Design}

We conducted an online experiment, following a 2 (consumption experience valence: positive vs. negative) $\times 2$ (aggregated rating valence: positive vs. negative) $\times 2$ (individual reviews valence: positive vs. negative) between-subjects design. The study implemented a scenariobased approach, which is frequently used for research into negative consumption experiences and the service industry (Kim and Jang, 2014; Liao, 2007; Roschk and Kaiser, 2013). Specifically, the hotel industry was selected as the research context, for its prominence in eWOM research (e.g. Baka, 2016; Chong et al., 2018).

To best serve the research purpose and recruit appropriate participants that can relate themselves to the scenarios, we set up a series of screening questions at the beginning of the experiment (Hunt and Scheetz, 2018; Nieto-García et al., 2017). We first asked the participants about their recent hotel-staying experience, holiday experience and number of visits in Orlando, i.e. the destination used in our experimental stimuli. We screened out the participants who had not stayed in a hotel in the previous 12 months or had not gone on a holiday in the previous 24 months. We also screened out participants who live in Orlando or have been to Orlando several times to avoid the local knowledge bias. Participants were then asked about their online review reading, with frequency on a 7-point scale, from never to every time (i.e. how often do you read online reviews before booking hotels? and how often do you give online reviews about your hotel-staying experience?). Participants who were inexperienced with online review reading and giving (i.e. frequency below sometimes) were filtered out. After the screening process, we asked the participants to imagine they had gone on a holiday and stayed in a hotel for four nights. To enhance the realism of the scenario, we chose Orlando in Florida as the hotel location. Orlando was the first destination to receive more than 60 million visitors in the US and is also one of the most popular holiday destinations for both domestic and international markets (Gollan, 2015).

We recruited all study participants from the US through Mechanical Turk. We then provided the respondents with a statement describing the criteria of a 3-star hotel for them to read and complete a comprehension question, which aimed to standardise their expectations in the experimental setting (according to the criteria above, please select which of the following facilities or items a 3-star hotel does not have to provide: towels, a colour TV, a chocolate bar or a hot beverage). We then manipulated the consumption experience valence by randomly 
assigning participants to reading about either a positive or negative 3-star hotel stay. We further checked the participants' attention and comprehension of the scenarios by asking them which heading was not used in the scenario (building/room, furniture/equipment, food or services) and the hotel's name in the scenario (Emerald Hotel, Ruby Hotel, Diamond Hotel and Platinum Hotel). Finally, the participants received fictitious TripAdvisor eWOM about the hotel. The eWOM information presented included an aggregated rating (randomly assigned: positive or negative) and three recent individual reviews (randomly assigned: three positive or three negative). In line with previous studies, we used TripAdvisor as an actual brand in the scenario to avoid consumers' first impression bias of an unknown review site and its credibility; randomisation neutralised the impact of participants' prior knowledge of TripAdvisor on the results (López-López and Parra, 2016; Tsao et al., 2015). The study also aims to examine the congruent/incongruent valences of aggregated rating and individual reviews and their interactive effects with the valence of personal experience on the consumers' post-purchase evaluation. To ensure realism, we chose to use 4 out of 5 ("very good" based on TripAdvisor criteria) and 2 out of 5 ("poor" based on TripAdvisor criteria) to present the positive and negative aggregated rating rather than extreme cases (i.e. 5 out of 5 and 1 out of 5). It might be unrealistic for a high- (low-) rated hotel to provide low (high) quality services and receive multiple negative (positive) individual reviews. Meanwhile, the number of hotels and the hotel's ranking in the local area and distributions of TripAdvisor 5-point rating scale were adopted from TripAdvisor's real data in Orlando. An example of a hotel-stay scenario is provided in Appendix 1. A questionnaire followed, including the scales of all dependent variables hypothesised in this study. To ensure the validity of the responses, we inserted three attention-checking questions in the middle of the scales (e.g. please select neither agree nor disagree). Figure 4 demonstrates the steps in the experimental design and the rationales of each step.

<Insert Figure 4 here>

\subsection{Manipulation and Realism Checks (Pilot and Pre-Test)}

We initially ran a pilot with 12 university postgraduate research students to test the readability and accuracy of the experimental design and questionnaire wording, and to estimate the duration of the experiment. The students were first invited to participate in the online 
experiment in a lab setting, make short notes about the issues identified and provide their completion time. The average completion time (including short note-taking) was about 18 minutes, with the quickest case being 12 minutes. A focus group discussion session then followed. The identified issues, including wording, number of attention-checking questions and font use in scenarios were discussed. We then revised the experimental stimuli and questionnaire by incorporating the suggestions drawn from the pilot. After the pilot, a pre-test was conducted with 180 respondents to ensure the scenarios were realistic and were accurately manipulated based on the experimental design. Consumption experience valence measures were adapted from Duprez et al. (2015) and aggregated rating and individual reviews valence measures from Antheunis et al. (2010). Realism checks (Table 2) showed that the situations in the scenarios were experimentally (how realistic the scenario was) and mundanely (how likely it was that the situation could happen in real life) realistic (Liao, 2007). Meanwhile, the results support the effectiveness of the valence of the Consumption Experience manipulation: $M_{\text {positive }}$ $=8.90, S D=1.13$ vs. $M_{\text {negative }}=1.72, S D=1.72 ; \mathrm{t}(178)=44.37, \mathrm{p}<.001$. The Aggregated Rating and Individual Reviews valences were successfully manipulated: $M_{\text {positive }}=5.25, S D=$ 1.61 vs. $M_{\text {negative }}=2.11, S D=1.53 ; \mathrm{t}(178)=12.34, \mathrm{p}<.001 ;$ and $M_{\text {positive }}=5.31, S D=1.87$ vs. $M_{\text {negative }}=1.98, S D=1.40 ; \mathrm{t}(178)=13.75, \mathrm{p}<.001$, respectively.

<Insert Table 2 here>

\section{Data Analysis and Results}

For the main study, 671 participants using Mechanical Turk attempted to complete the online experiment. 239 were filtered out due to insufficient hotel staying and holiday experience or limited engagement with online reviews, or over much local knowledge about Orlando. 47 participants failed to correctly answer the comprehension and attention-checking questions and were screened out during the experiment. Additionally, 21 participants waived their participation in the middle of the experiment, representing incomplete responses. Furthermore, using the quickest case as a benchmark (12 minutes), we eliminated 17 responses that were completed within 10 minutes (the participants were still paid). After the elimination, the average completion time was 14 minutes 32 seconds, which is close to the estimated time from the pilot (i.e. 18 minutes, including note making). The final sample was therefore 347 participants (demographic details are shown in Table 3). The following constructs were 
assessed in the questionnaire following the experimental conditions: emotional intensity ( $\alpha$ $=.83$; López-López et al., 2014), perceived service quality ( $\alpha=.91$; Brady and Cronin, 2001; Liu and Jang, 2009), brand image ( $\alpha=.85$; Chiang and Jang, 2007), perceived credibility of the review site ( $\alpha=.89$; Cheung et al., 2009), and eWOM-giving intention ( $\alpha=.95$; Leung et al., 2015). Appendix 2 presents the scale items for all the variables.

<Insert Table 3 here>

Our hypotheses refer to the congruence/incongruence of the valences between three independent variables: Consumption Experience, Aggregated Rating and Individual Reviews. The eight experimental conditions were divided into four groups (i.e. levels of the independent variables' valence congruence/incongruence, in H1, H2 and H4) for hypothesis testing, and coded in the statistical system before the analysis, as shown in Table 4.

<Insert Table 4 here>

Our initial analysis addressed polarisation effects on emotional intensity, brand image, perceived service quality and perceived credibility of the review site (e.g. Situation A should have a stronger impact on these variables than on the other scenarios). Although emotional intensity and perceived credibility of the review site are not valence-based, perceived service quality and brand image depend on consumption experience. Therefore, the analyses for perceived service quality (H1b) and brand image (H1c) were divided into positive and negative cases. Additionally, ANOVA was employed in examining H1, H2 and $\mathrm{H} 4$ as these hypotheses emphasise testing the mean differences of a dependent variable among four groups with different congruence/incongruence combinations among CE, AR and IR.

In testing $\mathrm{H} 1 \mathrm{a}$, the ANOVA results suggested that congruence/incongruence between $\mathrm{CE}, \mathrm{AR}$ and IR has a significant influence on emotional intensity $(\mathrm{F}(3,343)=14.10 ; \mathrm{p}<.001)$. A pairwise comparison test using the Bonferroni method confirmed the mean differences between the first (Situation A) and second (Situation C) highest points $\left(M_{\text {Situation A }}=5.06\right.$ and $\mathrm{SE}=.23$, $M_{\text {Situation C }}=4.44$ and SE $=.23$, and $\mathrm{p}<.05$; see Figure 5 in Appendix 3). Therefore, H1a was supported. Further, the results suggest that congruence/incongruence only influences service 
quality perception in a positive case $(\mathrm{F}(3,166)=6.23 ; \mathrm{p}<.001)$ (negative case: $\mathrm{F}(3,173)=.58$; $\mathrm{p}>.05)$. As the post hoc test did not support the significance of polarisation in the positive case $\left(M_{\text {Situation A }}=6.23\right.$ and $\mathrm{SE}=.32 ; M_{\text {Situation } \mathrm{C}}=5.84$ and $\mathrm{SE}=.32$, and $\mathrm{p}>.05 ;$ see Figure 6 in Appendix 3), H1b was rejected. Congruence/incongruence also significantly influenced brand image in both the positive $(\mathrm{F}(3,166)=12.85 ; \mathrm{p}<.001)$ and negative $(\mathrm{F}(3,173)=8.17 ; \mathrm{p}<.001)$ cases. The polarisation effects were significant in both cases (positive: $M_{\text {Situation A1 }}=6.51$ and $\mathrm{SE}=.18, M_{\text {Situation } \mathrm{C} 1}=5.58$ and $\mathrm{SE}=.18$, and $\mathrm{p}<.05$; negative: $M_{\text {Situation } \mathrm{A} 2}=2.00$ and $\mathrm{SE}=.17$, $M_{\text {Situation } \mathrm{C} 2}=2.76$ and SE $=.17$, and $\mathrm{p}<.005$; see Figure 7 in Appendix 3), supporting H1c. Similar to the statistical approach used in testing H1a, we found congruence/incongruence also significantly influenced the perceived credibility of the review site $(F(3,343)=30.49 ; \mathrm{p}<.001)$, and the polarisation effects were also significant $\left(M_{\text {Situation A }}=5.60\right.$ and $\mathrm{SE}=.24 ; M_{\text {Situation C }}=$ 4.42 and $\mathrm{SE}=.24$, and $\mathrm{p}<.001$ ), confirming H1d (see Figure 8 in Appendix 3).

To determine the impact of AR and IR on post-purchase evaluation, we compared the effects of CE-AR congruence with CE-IR congruence. According to the analysis for H1, congruence/incongruence between CE, AR and IR significantly influenced emotional intensity, brand image and the perceived credibility of the review site, whereas perceived service quality was not affected by congruence/incongruence. Therefore, $\mathrm{H} 2 \mathrm{~b}$ was rejected. Comparing the impact of CE-AR and CE-IR on emotional intensity, the results from a Bonferroni test supported $\mathrm{H} 2 \mathrm{a}\left(M_{\text {Situation } \mathrm{C}}=4.44\right.$ and $\mathrm{SE}=.23, M_{\text {Situation B }}=3.75$ and $\mathrm{SE}=.23$, and $\left.\mathrm{p}<.05\right)$. Further, the effects of CE-AR and CE-IR on brand image were compared for both positive and negative cases. Congruence between CE and IR had a stronger influence on brand image compared with $\mathrm{CE}$ and $\mathrm{AR}$ congruence (positive: $M_{\mathrm{Situation} \mathrm{C} 1}=5.58$ and $\mathrm{SE}=.18, M_{\mathrm{Situation} \mathrm{B} 1}=$ 4.84 and $\mathrm{SE}=.18$, and $\mathrm{p}<.05$; negative: $M_{\text {Situation } \mathrm{C} 2}=2.76$ and $\mathrm{SE}=.17, M_{\mathrm{Situation} \mathrm{B} 2}=3.65$, and $\mathrm{SE}=.17$, and $\mathrm{p}<.05)$. Hence, H2c was supported. Further, CE-IR valence congruence had a stronger influence on the perceived credibility of the review site than did CE-AR congruence $\left(M_{\text {Situation } \mathrm{C}}=4.42\right.$ and $\mathrm{SE}=.24, M_{\text {Situation } \mathrm{B}}=3.67$ and $\mathrm{SE}=.24$, and $\left.\mathrm{p}<.05\right)$, confirming $\mathrm{H} 2 \mathrm{~d}$.

$\mathrm{H} 3$ emphasises the differences between the effects of aggregated rating valence on multiple dependent variables (i.e. brand image, emotional intensity and perceived service quality). We therefore employed MANOVA instead of ANOVA to conduct the analysis. The results of the MANOVA show that AR had a stronger impact on brand image $(F(1,345)=4.20 ; p<.05)$ compared with emotional intensity $(\mathrm{F}(1,345)=.46 ; \mathrm{p}>.05)$ and perceived service quality $(\mathrm{F}$ $(1,345)=021 ; p>.05)$. This is in line with H3. Further ANOVA suggested that congruence/incongruence significantly influenced eWOM-giving intention $(\mathrm{F}(3,343)=3.76$; 
$\mathrm{p}<.001)$. By comparing the difference between the highest and second-highest mean values through a post hoc test, the results indicated that three-way congruence leads to significantly higher eWOM-giving intention $\left(M_{\text {Situation A }}=5.46\right.$ and $\mathrm{SE}=.19, M_{\text {Situation C }}=4.97$ and $\mathrm{SE}=.19$, and $\mathrm{p}<.005$; see Figure 9 in Appendix 3). Hence, H4a was supported. As to whether consumers avoid giving eWOM when the valence of their consumption experience is opposite to the valences of IR and AR, a pairwise comparison revealed an insignificant impact $\left(M_{\text {Situation D }}=\right.$ 4.66 and $\mathrm{SE}=.19$, and $M_{\mathrm{Situation} \mathrm{B}}=4.60$ and $\mathrm{SE}=.19$, and $\mathrm{p}>.05$; see Figure 9 in Appendix 3). H4b was rejected.

To examine the association between the post-evaluation dimensions and eWOM-giving intention, we employed regression analysis in testing $\mathrm{H} 5$ to $\mathrm{H} 8$. The results indicated that emotional intensity $\left(\mathrm{F}(1,345)=48.15, \mathrm{p}<.001, \mathrm{R}^{2}=.12\right)$, perceived service quality $(\mathrm{F}(1,345)$ $\left.=25.58, \mathrm{p}<.001, \mathrm{R}^{2}=.07\right)$, brand image $\left(\mathrm{F}(1,345)=17.17, \mathrm{p}<.001, \mathrm{R}^{2}=.05\right)$ and the perceived credibility of the review site $\left(\mathrm{F}(1,345)=14.89, \mathrm{p}<.001, \mathrm{R}^{2}=.04\right)$ positively influence eWOM-giving intention. Therefore, hypotheses 5 to 8 were supported. To identify any potential mediation effects of post-purchase evaluation in consumption experience-eWOM information interaction and eWOM-giving intention, we also tested the moderated moderated mediation (i.e. $\mathrm{CE} / \mathrm{IR} / \mathrm{AR}$ three-way interaction mediation) of each evaluative construct using SPSS PROCESS (Hayes, 2013). We find that only brand image mediates CE, IR and AR interaction and eWOM-giving intention (total effects model: $\mathrm{F}=39.91, \mathrm{p}<.001$; moderated moderated mediation: $\beta=0.234$; $\mathrm{CI}_{\mathrm{Boot}}=0.0010,0.0544$; $\mathrm{SE}_{\mathrm{Boot}}=0.0140$ ) but the mediation effects are not significant for emotional intensity (total effects model: $F=6.49, p<.001$; moderated moderated mediation: $\beta=0.0238 ; \mathrm{CI}_{\mathrm{Boot}}=-0.0207,0.0717 ; \mathrm{SE}_{\mathrm{Boot}}=0.234$ ), perceived service quality (total effects model: $\mathrm{F}=101.48, \mathrm{p}<.001$; moderated moderated mediation: $\left.\beta=0.0160 ; \mathrm{CI}_{\mathrm{Boot}}=-0.0221,0.0525 ; \mathrm{SE}_{\mathrm{Boot}}=0.0190\right)$ and the perceived credibility of the site (total effects model: $F=19.20, p<.001$; moderated moderated mediation: $\beta=0.0040$; $\left.\mathrm{CI}_{\text {Boot }}=-0.0082,0.0221 ; \mathrm{SE}_{\text {Boot }}=0.0073\right)$.

In sum, the results support H1 (a, c, d), H2 (a, c, d), H3, H4a, H5, H6, H7 and H8, but H1b, $\mathrm{H} 2 \mathrm{~b}$ and $\mathrm{H} 4 \mathrm{~b}$ were not supported.

\section{Discussion}

Based on the foundations of social comparison theory and information processing, we examined the impact of eWOM information on consumers' post-purchase evaluation and 
behaviour. Given our unique approach, we are able to highlight psychological mechanisms of the consumption experience and eWOM information in the post-purchase phase, and we thus offer the following.

First, according to social comparison theory and polarisation effects, the interactive effects of consumption experience and eWOM received post-purchase lead to emotional, cognitive and behavioural polarisation. More precisely, when the valences of consumption experience, aggregated rating and individual reviews are congruent, consumers experience stronger emotions, develop more extreme perceptions of the brand and consolidate their trust in the eWOM media. This result is important because it shows that consumers not only judge the service received based on their consumption experience, but also consider the experience of others when evaluating the service. Review sites provide platforms for comparison with other consumers in order to seek similarities and actualise self-confirmation. Through emotional polarisation, consumers feel better when they have a positive experience and worse when they have a negative one, which suggests that the emotional judgement is no longer objective. As consumption emotion significantly influences consumer satisfaction (Westbrook and Oliver, 1991), this finding reveals that consumption emotion could vary in light of any information intervention in the post-purchase stage. Brand image is also subject to polarisation effects. This suggests that brand image combines "what I think about the brand" and "what others think about the brand" (Cantallops and Salvi, 2014). Hence, congruence in self-others comparison helps consumers to confirm their beliefs about the brand. From a managerial perspective, service providers need to maintain a consistent service standard and monitor eWOM, thereby more efficiently developing a good reputation. Further, media evaluation is a specific dimension of consumers' social comparison in the eWOM context. In the post-purchase stage, consumers have a stronger voice when judging the credibility of eWOM media. Therefore, media owners need to carry out regular monitoring of the information disclosed via eWOM media and actively assist in the investigation of any cases of defamation reported. If consumers continue to find inconsistencies between their own experience and eWOM, they might distrust the medium and discontinue its use. Additionally, in a consumption-related evaluation, perceived service quality is not influenced by consistency between personal experience and received eWOM. This could be explained by the suggestion that perceived service quality represents the cognitive evaluation of the service received, and cognition is more objective than other types of evaluation in which emotions predominate (e.g. emotional intensity and brand image) (DePaula and Dourish, 2005). In other words, perceived service quality is largely 
dependent on personal consumption experience and cannot be changed significantly, regardless of what others say (namely, eWOM).

Second, our findings suggest that eWOM information influences consumers' evaluation in the post-purchase stage, although individual reviews seem to be relatively more important than aggregated rating. When consumers compare themselves with others based on personal experience and eWOM received post-purchase, they pay more attention to individual reviews than to aggregated rating, because individual reviews appear to be more relevant and seem to provide more meaningful cues for engaging in social comparison. Therefore, consumers are more attuned to whether their personal experience is consistent with the individual reviews of other consumers. Such a tendency in processing eWOM information is reflected in the evaluation of emotion, brand and media. However, similar to polarisation effects, perceived service quality is not influenced, due to the objective nature of service quality judgements. Nonetheless, this study indicates that, in terms of consumption-related evaluation, aggregated rating has a greater influence on brand image than have consumption emotion and perceived service quality. Brand image is a coalition of how a brand is perceived based on subjective experience and objective opinions. Therefore, it is essential that, as business entities, service providers make an effort in developing a positive aggregated rating for themselves on review sites. Even if in situations in which consumers have a negative experience with the service provider, a positive aggregated rating could potentially rescue the damaged brand image and result in a second chance for the service provider.

Third, we shed light on the dynamics of personal experience and received eWOM in eWOMgiving behaviour. We proposed spiral of silence effects to explain the eWOM mechanism when receiving eWOM information in the post-purchase stage. However, the spiral of silence is reflected in consumers "conforming with the majority", rather than "avoiding being in the minority". In other words, consumers have a higher eWOM-giving intention when there is congruence between the valences of consumption experience, aggregated rating and individual reviews. This is similar to the attitudinal/emotional polarisation identified before. Consumers are also more motivated to perform the behaviour that is widely acknowledged by others (Yeh and Choi, 2011). However, they do not seem to be over-cautious about being isolated from the majority in terms of voicing their perspectives through eWOM (Wetzer et al., 2007). This could be explained by the minimum impact of aggregated rating in the post-purchase stage. More specifically, since consumers pay little attention to aggregated rating, there is very little difference between personal experience being incongruent with aggregated rating and 
individual reviews and personal experience only being congruent with aggregated rating. Therefore, such insignificant effects resulting from congruence/incongruence are also reflected in eWOM-giving intention. Furthermore, we identified a positive association between the dimensions of post-purchase evaluation and eWOM-giving. The positive relationship between emotional intensity and eWOM suggests that eWOM-giving needs to be triggered by sufficiently strong consumption emotions, in both positive and negative cases. Although emotional intensity fluctuates when eWOM information intervenes, the residual emotional intensity still positively affects eWOM-giving intention. Perceived service quality and brand image also positively influence eWOM-giving, which reveals a positivity bias in eWOMgiving. This tendency has been identified in previous eWOM studies, suggesting that consumers are more likely to talk about a positive than a negative consumption experience (Lee-Won et al., 2014; Utz, 2015). Moreover, the positive relationship between the perceived credibility of eWOM media and eWOM-giving intentions emphasises that review sites need to maintain information authenticity. Otherwise, consumers could easily switch to similar review sites if they are perceived as more credible. Contributing to authentic and credible sites could be seen as the embodiment of consumer ethics in eWOM media consumption (Hassan et al., 2013; Sebastiani et al., 2013).

\section{Conclusions}

\subsection{Theoretical Contributions}

We take an innovative perspective in examining the impact of eWOM information on the postpurchase stage that revolutionises the tradition of investigating the power of pre-purchase eWOM. eWOM received and its interactions with personal consumption experiences have a significant impact upon post-purchase evaluation and eWOM-giving behaviour, and highlight polarisation effects at the emotional, brand and behavioural levels. Our findings refresh the understanding of the role that eWOM plays in the decision-making process and confirm that purchase is not the last stage at which eWOM matters. Reconceptualising post-purchase evaluation as a multidimensional concept and categorising post-purchase evaluation into consumption-related and media-related dimensions allow us to offer further insights. The multidimensionality of post-purchase evaluation emphasises the digital nature of eWOM and reflects the modernity of consumer behaviour in the information age. By comparing consistency between a personal consumption experience and the eWOM available on review 
sites, consumers re-evaluate the review sites and adjust their engagement level with eWOM media. Unlike other evaluative dimensions that are related to consumption and a particular service provider, media evaluation adds a new domain to consumers' post-purchase evaluation when eWOM is involved. More importantly, most studies employing social comparison theory in service research focus on consumers' vertical social comparison, namely, whether they are in a better or worse situation through self-others comparison. We push the boundaries of the application of social comparison theory in the eWOM context by emphasising horizontal comparison and examining the similarity of valences of the consumption experience and eWOM information. We also highlight the impact of social comparison elicited by eWOM received on multiple dimensions of post-purchase evaluation. It therefore follows that the effects of social comparison might influence consumers' cognitive, emotional and behavioural levels in the post-purchase stage. Moreover, by comparing AR and IR, our study suggests that individual reviews are the main driver in the post-purchase stage. Although aggregated rating is no longer as important as it is in the pre-purchase stage, it still plays an irreplaceable role in constructing a positive brand image, even in the post-purchase stage. We thus pave the way for a whole new understanding of how consumers evaluate eWOM information pre-purchase, when both AR and IR are important to decision-making.

\subsection{Managerial Implications}

From a managerial perspective, we offer fresh insights. First, service providers, in general, should keep in mind that online reviews not only provide important cues to ease consumers' decision-making in the pre-purchase stage but also act as references for consumers and shape their post-purchase evaluations. Therefore, service providers need to make effort in maintaining service standards, so as to ensure that consumers reach a consensus on shared eWOM information, thereby consolidating the positive evaluations and enhancing the chance of consumers' positive eWOM-giving. Second, our findings offer separate guidelines for service providers that are in different circumstances of establishing online their reputation. More precisely, for businesses that usually enjoy a good reputation on eWOM media, when negative reviews are produced, they ought to conduct an internal review promptly and eliminate the possibility of negative reviews caused by lowered service standards. Service providers also need to provide superior service and encourage consumers to share positive reviews, thereby neutralising or reducing the effects of negative feedback. This needs to be done in a timely manner, as consumers' perceptions and emotions could be polarised. Once 
negative reviews gain momentum, it takes longer to regain a consistent standard and this might damage the brand image in the long run. On the other hand, we are able to offer guidance to underperforming companies on review sites. Such companies should strive to stimulate the generation of positive reviews, so as to create a positive trend. Once such a trend is established, consumers are more likely to empathise with positive reviews; this, in turn, could lead to more positive eWOM. Ultimately, in the post-purchase stage, consumers pay little attention to aggregated rating. Therefore, although a business's aggregated rating might not be overly positive, consumers could still potentially share positive individual reviews in the presence of other positive individual reviews. Needless to say, it is imperative that firms provide consistent good-quality service. Third, since post-purchase evaluation contributes to eWOM-giving, service providers also need to endeavour to maintain a high standard of service to facilitate consumers' positive evaluation. At an emotional level, service providers could strive to delight (and surprise in a positive manner) customers (e.g. by providing a personalised welcome card and complimentary gifts at the check-out stage), thereby maximising the positive emotional intensity when consumers are still on the site and increasing the opportunity of having those consumers share their positive experiences via eWOM. For firms seeking to build their brands, there is value in ensuring the consistency of content that the firm receives on review sites. After all, the brand image captures both the short-term and long-term performances of the service provider. Meanwhile, service providers need to use online reviews as a diagnostic tool for gauging the service quality and take prompt restorative action when negative online reviews occur. Fourth, service providers need to work closely with third-party infomediaries to conduct regular monitoring and to control the authenticity and credibility of information about the service provider. While eWOM media owners need to actively cooperate with service providers and investigate the suspicious smears to ensure that the eWOM information available on their media is credible and fair. This will lead to a win-win situation in which both service providers and eWOM media achieve sustainable development and maintain the interactivity of the platform.

\subsection{Limitations and Future Research}

Although this study adopted a pioneering angle when investigating the role of eWOM information on review sites in the post-purchase stage, it has some limitations. First, it focuses on horizontal social comparison (i.e. similarity comparison) between eWOM received and the consumption experience in the post-purchase stage. Future research could further explore the 
effects of vertical comparison (i.e. whether personal experience was better or worse than others') in the eWOM setting and better understand consumers' psychological mechanisms in making self-others comparison. Second, we manipulated and standardised consumption experience through a scenario-based approach. Future research could employ the techniques of field experiment and examine effects of actual consumption experience at different satisfaction levels (e.g. highly satisfactory, moderately satisfactory, unsatisfactory and highly unsatisfactory) on post-purchase evaluation and eWOM-giving behaviour. Comparing to scenario-based approach, field experiment is particularly useful in capturing nuanced differences in emotional evaluation (e.g. emotional intensity). Meanwhile, as we manipulated different service variations (e.g. equipment, facilities and services) to represent the overall consumption experience valence, future research could further examine the social comparison triggered by different service attributes and its effects on consumers' evaluation in different dimensions. Third, the single-service setting on only one eWOM platform limits the generalisability of the findings, specifically as social comparison could be highly platformspecific due to differences in the available social capital (Phua et al., 2017). Future studies should test different research settings, since product categories and customer involvement could influence social comparison, and extend the research to other eWOM platforms, such as social networking sites (Mudambi and Schuff, 2010; Wangenheim and Bayón, 2004). Fourth, this study focuses on the interaction between consumers and eWOM information on review sites in the post-purchase stage. Review sites have started to allow service providers to communicate with eWOM-givers directly, although differentiated responses (i.e. whether the service provider gives similar or distinctive responses to different consumers) from the service provider could potentially trigger another round of social comparison (Liu et al., 2019). Future research could explore the social comparison elicited by the interpersonal interaction of eWOM-givers and business representatives on review sites and the implications for subsequent consumer evaluation (Yang et al., 2004). Fifth, eWOM-giving intention was only measured through a scenario-based experiment, which opens the possibility of future research bridging the intention-behaviour gap through other methods (e.g. using real data, memory recall and a large-scale survey) (Quan-Haase and Sloan, 2017). 


\section{References}

Aggarwal, R. and Singh, H. (2013), "Differential influence of blogs across different stages of decision making: The case of venture capitalists", MIS Quarterly, Vol. 37 No. 4, pp.1093-1112.

Alexandrov, A., Lilly, B. and Babakus, E. (2013), "The effects of social-and self-motives on the intentions to share positive and negative word of mouth", Journal of the Academy of Marketing Science, Vol. 41 No. 5, pp. 531-546.

Allen, A. M., Brady, M. K., Robinson, S. G. and Voorhees, C. M. (2015), “One firm's loss is another's gain: capitalizing on other firms' service failures", Journal of the Academy of Marketing Science, Vol. 43 No. 5, pp. 648-662.

Andsager, J. L. and White, H. A. (2007), Self versus others: Media, messages, and the thirdperson effect, Erlbaum, Mahwah, NJ.

Antheunis, M. L., Valkenburg, P. M. and Peter, J. (2010), "Getting acquainted through social network sites: Testing a model of online uncertainty reduction and social attraction", Computers in Human Behavior, Vol. 26 No. 1, pp. 100-109.

Antonetti, P., Crisafulli, B. and Maklan, S. (2018), "Too good to be true? Boundary conditions to the use of downward social comparisons in service recovery", Journal of Service Research, Vol. 21 No. 4, pp. 438-455.

Argo, J. J., White, K. and Dahl, D. W. (2006), "Social comparison theory and deception in the interpersonal exchange of consumption information", Journal of Consumer Research, Vol. 33 No. 1, pp. 99-108.

Askay, D.A., (2015). "Silence in the crowd: The spiral of silence contributing to the positive bias of opinions in an online review system", New Media \& Society, Vol. 17 No. 11, pp. 1811-1829.

Bachleda, C. and Berrada-Fathi, B. (2016), "Is negative eWOM more influential than negative pWOM?”, Journal of Service Theory and Practice, Vol. 26 No. 1, pp. 109-132.

Baka, V. (2016), "The becoming of user-generated reviews: Looking at the past to understand the future of managing reputation in the travel sector", Tourism Management, Vol. 53, pp. 148-162.

Bearden, W. O. and Rose, R. L. (1990), "Attention to social comparison information: An individual difference factor affecting consumer conformity", Journal of Consumer Research, Vol. 16 No. 4, pp. 461-471.

Bhattacherjee, A. and Premkumar, G. (2004), "Understanding changes in belief and attitude toward information technology usage: A theoretical model and longitudinal test". MIS Quarterly, Vol. 28 No. 2, pp. 229-254.

Bigne, J.E., Sanchez, M.I. and Sanchez, J., (2001), "Tourism image, evaluation variables and after purchase behaviour: inter-relationship", Tourism Management, Vol. 22 No. 2, pp.607-616.

Borgida, E. and Nisbett, R.E., (1977), "The differential impact of abstract vs. concrete information on decisions", Journal of Applied Social Psychology, Vol. 7 No. 3, pp.258271. 
Brady, M.K. and Cronin Jr, J.J., (2001), "Some new thoughts on conceptualizing perceived service quality: a hierarchical approach", Journal of Marketing, Vol. 65 No. 3, pp.3449.

Camilleri, A.R., (2017), "The presentation format of review score information influences consumer preferences through the attribution of outlier reviews", Journal of Interactive Marketing, Vol. 39, pp.1-14.

Cantallops, A.S. and Salvi, F., (2014), "New consumer behavior: A review of research on eWOM and hotels", International Journal of Hospitality Management, Vol. 36, pp.4151.

Carù, A. and Cova, B., (2003), "Revisiting consumption experience: A more humble but complete view of the concept", Marketing Theory, Vol. 3 No. 2, pp.267-286.

Catino, M. and Patriotta, G. (2013), "Learning from errors: Cognition, emotions and safety culture in the Italian air force", Organization Studies, Vol. 34 No. 4, pp. 437-467.

Chakravarty, A., Liu, Y. and Mazumdar, T. (2010), "The differential effects of online wordof-mouth and critics' reviews on pre-release movie evaluation", Journal of Interactive Marketing, Vol.24 No.3, pp.185-197.

Chan, H. and Cui, S. (2011), "The contrasting effects of negative word of mouth in the post consumption stage", Journal of Consumer Psychology, Vol. 21 No. 3, pp. 324-337.

Chawdhary, R. and Dall'Olmo Riley, F., (2015), "Investigating the consequences of word of mouth from a WOM sender's perspective in the services context", Journal of Marketing Management, Vol. 31 No. 9-10, pp.1018-1039.

Chen, C. H., Nguyen, B., Klaus, P. P. and Wu, M. S. (2015), "Exploring electronic word-ofmouth (eWOM) in the consumer purchase decision-making process: the case of online holidays-evidence from United Kingdom (UK) consumers", Journal of Travel \& Tourism Marketing, Vol. 32 No. 8, pp.953-970.

Chen, H. T. (2018), "Spiral of silence on social media and the moderating role of disagreement and publicness in the network: Analyzing expressive and withdrawal behaviors", New Media \& Society, Vol. 20 No. 10, pp. 3917-3936.

Chen, H.B., Yeh, S.S. and Huan, T.C., (2014), "Nostalgic emotion, experiential value, brand image, and consumption intentions of customers of nostalgic-themed restaurants" Journal of Business Research, Vol. 67 No. 3, pp.354-360.

Cheung, C. M., Lee, M. K. and Rabjohn, N. (2008), "The impact of electronic word-of-mouth: The adoption of online opinions in online customer communities", Internet research, Vol. 18 No. 3, pp. 229-247.

Cheung, M.Y., Luo, C., Sia, C.L. and Chen, H., (2009), "Credibility of electronic word-ofmouth: Informational and normative determinants of on-line consumer recommendations", International Journal of Electronic Commerce, Vol. 13 No. 4, pp.9-38.

Chiang, C.F. and Jang, S.S., (2007), "The effects of perceived price and brand image on value and purchase intention: Leisure travellers' attitudes toward online hotel booking", Journal of Hospitality \& Leisure Marketing, Vol. 15 No. 3, pp.49-69.

Choi, Y. K., Seo, Y. and Yoon, S. (2017), "E-WOM messaging on social media: social ties, temporal distance, and message concreteness", Internet Research, Vol. 27 No. 3, pp. 495-505. 
Chong, A. Y. L., Khong, K. W., Ma, T., McCabe, S. and Wang, Y. (2018), “Analyzing key influences of tourists' acceptance of online reviews in travel decisions", Internet Research, Vol. 28 No. 3, pp. 564-586.

Chu, S.C. and Kamal, S., (2008), "The effect of perceived blogger credibility and argument quality on message elaboration and brand attitudes: An exploratory study", Journal of Interactive Advertising, Vol. 8 No. 2, pp.26-37.

Dahl, D. (2013), "Social influence and consumer behaviour", Journal of Consumer Research, Vol. 40 No. 2, pp.iii-v.

DePaula, R. and Dourish, P., (2005), Cognitive and cultural views of emotions. Proc. HCIC.

Doh, S.J. and Hwang, J.S., (2009), "How consumers evaluate eWOM (electronic word-ofmouth) messages”, Cyber Psychology \& Behavior, Vol. 12 No. 2, pp.193-197.

Duprez, C., Christophe, V., Rime, B., Congard, A. and Antoine, P. (2015), "Motives for the social sharing of an emotional experience", Journal of Social and Personal Relationships, Vol. 32 No. 6, pp. 757-787.

Festinger, L. (1962), “A Theory of Cognitive Dissonance”, Stanford University Press, Stanford, CA.

Festinger, L., (1954), “A theory of social comparison processes”, Human Relations, Vol. 7 No. 2, pp.117-140.

Field, A. (2009), Discovering Statistics using SPSS, 3rd ed., Sage, London.

Filieri, R. and McLeay, F., (2014), "E-WOM and accommodation: An analysis of the factors that influence travelers' adoption of information from online reviews", Journal of Travel Research, Vol. 53 No. 1, pp.44-57.

Fogg, B.J., Soohoo, C., Danielson, D.R., Marable, L., Stanford, J. and Tauber, E. (2003), "How do users evaluate the credibility of web sites? A study with over 2,500 participants", Proceedings of the 2003 Conference on Designing for User Experiences, San Francisco, CA, pp. 1 - 15.

Gearhart, S. and Zhang, W. (2015), ““Was it something I said?"“No, it was something you posted!" A study of the spiral of silence theory in social media contexts", Cyberpsychology, Behavior, and Social Networking, Vol. 18 No. 4, pp. 208213.

Glynn, C.J., Hayes, A.F. and Shanahan, J., (1997), "Perceived Support for One's Opinions and Willingness to Speak Out: A Meta-Analysis of Survey Studies on the" Spiral of Silence", Public Opinion Quarterly, Vol. 61 No. 3, pp.452-463.

Goethals, G. R. (1986), "Social comparison theory: Psychology from the lost and found", Personality and Social Psychology Bulletin, Vol. 12 No. 3, pp.261-278.

Gollan. D. (2015), "Luxury lifts Orlando to record 62 million visitors", R/OL, April 10, available at: http://www.forbes.com/sites/douggollan/2015/04/10/orlando-tops-invisitors-with-62-million-mayoral-bliss/\#69bd604c25a7.

Grace, D. and O'Cass, A., (2004), "Examining service experiences and post-consumption evaluations", Journal of Services Marketing, Vol. 18 No. 6, pp.450-461.

Grover, V., Cheon, M.J. and Teng, J.T., (1996). "The effect of service quality and partnership on the outsourcing of information systems functions". Journal of Management Information Systems, Vol. 12 No. 4, pp.89-116. 
Gvili, Y. and Levy, S. (2016), "Antecedents of attitudes toward eWOM communication: differences across channels", Internet Research, Vol. 26 No. 5, pp. 1030-1051.

Haferkamp, N. and Krämer, N.C., (2011), "Social comparison 2.0: Examining the effects of online profiles on social-networking sites" Cyberpsychology, Behavior, and Social Networking, Vol. 14 No. 5, pp.309-314.

Hassan, L., Shaw, D., Shiu, E., Walsh, G. and Parry, S., (2013), "Uncertainty in ethical consumer choice: a conceptual model", Journal of Consumer Behaviour, Vol. 12 No. 3, pp.182-193.

Hayes, A.F. (2013), Introduction to Mediation, Moderation and Conditional Process Analysis, The Guilford Press, New York, NY.

Hennig-Thurau, T., Gwinner, K.P., Walsh, G. and Gremler, D.D., (2004), "Electronic wordof-mouth via consumer-opinion platforms: what motivates consumers to articulate themselves on the internet?", Journal of Interactive Marketing, Vol. 18 No. 1, pp.3852.

Hess, R. L. and Ring, L. (2016), "The influence of the source and valence of word-of-mouth information on post-failure and post-recovery evaluations", Service Business, Vol. 10 No. 2, pp.319-343.

Hogg, M.K., Cox, A.J. and Keeling, K., (2000), "The impact of self-monitoring on image congruence and product/brand evaluation", European Journal of Marketing, Vol. 34 No. 5/6, pp.641-667.

Hood, K.M., Shanahan, K.J., Hopkins, C.D. and Lindsey, K.K., (2015), “The influence of interactivity on visit and purchase frequency: the moderating role of website informational features", Journal of Internet Commerce, Vol. 14 No. 3, pp.294-315.

$\mathrm{Hu}$, N., Pavlou, P.A. and Zhang, J. (2006), "Can online reviews reveal a product's true quality?: empirical findings and analytical modeling of online word-of-mouth communication", in Feigenbaum, J., Chuang, J. and Pennock, D. (Eds), Proceedings of the 7th ACM Conference on Electronic Commerce, ACM Press, New York, NY, pp. 324-330.

Hunt, N. C. and Scheetz, A. M. (2018), "Using MTurk to distribute a survey or experiment: Methodological considerations", Journal of Information Systems.

Ifie, K., Simintiras, A. C., Dwivedi, Y. and Mavridou, V. (2018), "How service quality and outcome confidence drive pre-outcome word-of-mouth", Journal of Retailing and Consumer Services, Vol. 44, pp. 214-221.

Islam, J. U., Rahman, Z. and Hollebeek, L. D. (2017), "Consumer engagement in online brand communities: A solicitation of congruity theory”, Internet Research, Vol. 28 No. 1, pp. $23-45$.

Jalilvand, M.R. and Samiei, N., (2012), "The effect of electronic word of mouth on brand image and purchase intention: An empirical study in the automobile industry in Iran”, Marketing Intelligence \& Planning, Vol. 30 No. 4, pp.460-476.

Jeong, E. and Jang, S. S. (2011), "Restaurant experiences triggering positive electronic wordof-mouth (eWOM) motivations", International Journal of Hospitality Management, Vol. 30 No. 2, pp. 356-366. 
Johnen, M., Jungblut, M. and Ziegele, M. (2018), "The digital outcry: What incites participation behavior in an online firestorm?", New Media \& Society, Vol. 20 No. 9, pp. 3140-3160.

Jun, J., Kang, J. and Hyun, S. S. (2017), "Effects of third-party certification on patrons' service quality evaluation in the luxury-restaurant industry", British Food Journal, Vol. 119 No. 4, pp.771-789.

Kang, M. (2010), "Measuring social media credibility: A study on a Measure of Blog Credibility", Institute for Public Relations, pp.59-68.

Kardes, F. (1994), “Consumer Judgment and Decision Processes,” in Wyer., R.S. and Srull. T. K. (Eds.) Handbook of Social Cognition, pp.399-466.

Kim, D., Jang, S. and Adler, H. (2015), "What drives café customers to spread eWOM? Examining self-relevant value, quality value, and opinion leadership", International Journal of Contemporary Hospitality Management, Vol. 27 No. 2, pp. 261-282.

Kim, J. H. and Jang, S. S. (2014), "A scenario-based experiment and a field study: A comparative examination for service failure and recovery", International Journal of Hospitality Management, Vol. 41, pp. 125-132.

Kim, M. and Lee, M. (2017), "Brand-related user-generated content on social media: the roles of source and sponsorship", Internet Research, Vol. 27 No. 5, pp. 1085-1103.

Kuo, Y.F., Wu, C.M. and Deng, W.J., (2009), “The relationships among service quality, perceived value, customer satisfaction, and post-purchase intention in mobile valueadded services", Computers in Human Behavior, Vol. 25 No. 4, pp.887-896.

Lee-Won, R.J., Shim, M., Joo, Y.K. and Park, S.G., (2014), "Who puts the best "face" forward on Facebook?: Positive self-presentation in online social networking and the role of self-consciousness, actual-to-total Friends ratio, and culture", Computers in Human Behavior, Vol. 39, pp.413-423.

Leung, X.Y., Bai, B. and Stahura, K.A., (2015), "The marketing effectiveness of social media in the hotel industry: A comparison of Facebook and Twitter2", Journal of Hospitality \& Tourism Research, Vol. 39 No.2, pp.147-169.

Lewis, R. C. and Chambers, R. E. (2000), Marketing Leadership in Hospitality, John Wiley, New York, NY.

Liao, H. (2007), "Do it right this time: The role of employee service recovery performance in customer-perceived justice and customer loyalty after service failures", Journal of Applied Psychology, Vol. 92 No. 2, pp.475-489.

Liu, H. and Jayawardhena, C (2018), "Consumption Emotion in eWOM and Media Choice: A Social Sharing of Emotion Perspective", Proceedings of 2018 American Marketing Association (AMA) Winter Academic Conference, New Orleans, LA, February 23-25, pp. D-11.

Liu, H., Jayawardhena, C., Dibb, S. and Ranaweera, C. (2019), "Examining the trade-off between compensation and promptness in eWOM-triggered service recovery: A restorative justice perspective", Tourism Management, Vol. 75, pp.381-392.

Liu, Y. and Jang, S.S., (2009), "Perceptions of Chinese restaurants in the US: what affects customer satisfaction and behavioral intentions?", International Journal of Hospitality Management, Vol. 28 No. 3, pp.338-348. 
Liu, Y. L. and Keng, C. J. (2014), "Cognitive dissonance, social comparison, and disseminating untruthful or negative truthful eWOM messages", Social Behavior and Personality: An International Journal, Vol. 42 No.6, pp.979-995.

Locke, K. D. (2003), "Status and solidarity in social comparison: Agentic and communal values and vertical and horizontal directions", Journal of Personality and Social Psychology, Vol. 84 No. 3, pp. 619-631.

Locke, K. D. (2005), "Connecting the horizontal dimension of social comparison with selfworth and self-confidence", Personality and Social Psychology Bulletin, Vol. 31 No. 6, pp. 795-803.

Locksley, A., Hepburn, C. and Ortiz, V. (1982), "Social stereotypes and judgments of individuals: An instance of the base-rate fallacy", Journal of Experimental Social Psychology, Vol. 18 No. 1, pp. 23-42.

López-López, I. and Parra, J. F. (2016), "Is a most helpful eWOM review really helpful? The impact of conflicting aggregate valence and consumer's goals on product attitude", Internet Research, Vol. 26 No. 4, pp. 827-844.

López-López, I., Ruiz-de-Maya, S. and Warlop, L., (2014), "When sharing consumption emotions with strangers is more satisfying than sharing them with friends", Journal of Service Research, Vol. 17 No. 4, pp.475-488.

Lord, C. G., Ross, L. and Lepper, M. R. (1979), "Biased assimilation and attitude polarization: The effects of prior theories on subsequently considered evidence", Journal of Personality and Social Psychology, Vol. 37 No. 11, pp. 2098-2109.

Luca, M. (2011), "Reviews, Reputation, and Revenue: The Case of Yelp.com", working paper [No. 12-016], Harvard Business School, Boston, September.

Ma, X., Khansa, L., Deng, Y. and Kim, S.S., (2013), "Impact of prior reviews on the subsequent review process in reputation systems", Journal of Management Information Systems, Vol. 30 No. 3, pp.279-310.

Mano, H. and Oliver, R.L., (1993), "Assessing the dimensionality and structure of the consumption experience: evaluation, feeling, and satisfaction", Journal of Consumer Research, Vol. 20 No. 3, pp.451-466.

Metzger, M. J., Flanagin, A. J., Eyal, K., Lemus, D. R. and McCann, R. M. (2003), “Credibility for the 21st century: Integrating perspectives on source, message, and media credibility in the contemporary media environment", Annals of the International Communication Association, Vol. 27 No. 1, pp. 293-335.

Mudambi, S.M. and Schuff, D., (2010), "Research note: What makes a helpful online review? A study of customer reviews on Amazon.com”, MIS Quarterly, pp.185-200.

Nandan, S. (2005), "An exploration of the brand identity-brand image linkage: A communications perspective", Journal of Brand Management, Vol. 12 No. 4, pp. 264278.

Nieto-García, M., Muñoz-Gallego, P. A. and González-Benito, Ó, (2017), “Tourists' willingness to pay for an accommodation: The effect of eWOM and internal reference price”, International Journal of Hospitality Management, Vol. 62, pp.67-77.

Nisbett, R.E. and Borgida, E., (1975), “Attribution and the psychology of prediction”, Journal of Personality and Social Psychology, Vol. 32 No. 5, pp.932. 
Noelle-Neumann, E. (1991), "The theory of public opinion: the concept of the spiral of silence", in Anderson, J.A. (Ed.), Communication Yearbook 14, Sage, Newbury Park, CA, pp. 256-287.

Oliver, R. L. (1977), "Effect of expectation and disconfirmation on postexposure product evaluations: An alternative interpretation", Journal of Applied Psychology, Vol. 62 No. 4, pp. 480-486.

Oliver, R. L. and Burke, R. R. (1999), "Expectation processes in satisfaction formation: A field study”, Journal of Service Research, Vol. 1 No. 3, ppt. 196-214.

Padgett, D. and Allen, D., (1997), "Communicating experiences: A narrative approach to creating service brand image", Journal of Advertising, Vol. 26 No. 4, pp.49-62.

Pan, X., Hou, L., Liu, K. and Niu, H., (2018), "Do reviews from friends and the crowd affect online consumer posting behaviour differently?", Electronic Commerce Research and Applications, Vol. 29, pp. 102-112.

Parasuraman, A., Zeithaml, V.A. and Berry, L.L., (1988), "SERVQUAL: A multiple-item scale for measuring consumer perception", Journal of Retailing, Vol. 64 No. 1, pp.12-40.

Park, C. and Lee, T. M. (2009), "Information direction, website reputation and eWOM effect: A moderating role of product type", Journal of Business Research, Vol. 62 No. 1, pp. 61-67.

Park, S.B. and Park, D.H., (2013), "The effect of low versus high variance in product reviews on product evaluation", Psychology \& Marketing, Vol. 30 No. 7, pp.543-554.

Parsell, M. (2008), "Pernicious virtual communities: Identity, polarisation and the Web 2.0", Ethics and Information Technology, Vol. 10 No. 1, pp. 41-56.

Petty, R. E. and Krosnick, J. A. (2014), Attitude strength: Antecedents and consequences, Psychology Press, New York, NY.

Phua, J., Jin, S.V. and Kim, J.J., (2017), "Gratifications of using Facebook, Twitter, Instagram, or Snapchat to follow brands: The moderating effect of social comparison, trust, tie strength, and network homophily on brand identification, brand engagement, brand commitment, and membership intention", Telematics and Informatics, Vol. 34 No.1, pp.412-424.

Purnawirawan, N., De Pelsmacker, P. and Dens, N. (2012), "Balance and sequence in online reviews: How perceived usefulness affects attitudes and intentions", Journal of Interactive Marketing, Vol. 26 No. 4, pp.244-255.

Purnawirawan, N., Eisend, M., De Pelsmacker, P. and Dens, N. (2015), "A meta-analytic investigation of the role of valence in online reviews", Journal of Interactive Marketing, Vol. 31, pp.17-27.

Qiu, L., Pang, J. and Lim, K.H., (2012), "Effects of conflicting aggregated rating on eWOM review credibility and diagnosticity: The moderating role of review valence", Decision Support Systems, Vol. 54 No. 1, pp.631-643.

Quan-Haase, A. and Sloan, L. (2017) "Introduction to the Handbook of Social Media Research Methods: Goals, Challenges and Innovations”, in Sloan, L. and Quan-Haase, A. (Ed.), The SAGE Handbook of Social Media Research Methods, SAGE Publications, London, pp. 1-9. 
Quaschning, S., Pandelaere, M. and Vermeir, I. (2014), "When consistency matters: The effect of valence consistency on review helpfulness", Journal of Computer-Mediated Communication, Vol.20 No. 2, pp.136-152.

Ranaweera, C. and Jayawardhena, C., (2014), "Talk up or criticize? Customer responses to WOM about competitors during social interactions", Journal of Business Research, Vol. 67 No. 12, pp.2645-2656.

Richins, M.L., (1991), "Social comparison and the idealized images of advertising” Journal of Consumer Research, Vol. 18 No. 1, pp.71-83.

Richins, M.L., (1995), "Social comparison, advertising, and consumer discontent", American Behavioral Scientist, Vol. 38 No. 4, pp.593-607.

Rimé, B., (2009), "Emotion elicits the social sharing of emotion: Theory and empirical review", Emotion Review, Vol. 1 No. 1, pp.60-85.

Rimé, B., Finkenauer, C., Luminet, O., Zech, E. and Philippot, P., (1998), "Social sharing of emotion: New evidence and new questions", European Review of Social Psychology, Vol. 9 No. 1, pp.145-189.

Rimé, B., Finkenauer, C., Luminet, O., Zech, E. and Philippot, P. (1998), "Social sharing of emotion: New evidence and new questions", European Review of Social Psychology, Vol. 9 No. 1, pp. 145-189.

Roschk, H. and Kaiser, S. (2013), "The nature of an apology: An experimental study on how to apologize after a service failure", Marketing Letters, Vol. 24 No. 3, pp. 293-309.

Sebastiani, R., Montagnini, F. and Dalli, D., (2013), "Ethical consumption and new business models in the food industry. Evidence from the Eataly case", Journal of Business Ethics, Vol. 114 No. 3, pp.473-488.

Shang, R. A., Chen, Y. C. and Chen, C. J. (2013), "The social and objective value of information in virtual investment communities", Online Information Review, Vol. 37 No. 4, pp. 498-517.

Shen, J. (2012), "Social comparison, social presence, and enjoyment in the acceptance of social shopping websites", Journal of Electronic Commerce Research, Vol 13 No. 3, pp. 198212.

Shen, Y., Shan, W. and Luan, J., (2018), "Influence of aggregated ratings on purchase decisions: an event-related potential study" European Journal of Marketing, Vol. 52 No. 1/2, pp.147-158.

Smeesters, D., Mussweiler, T. and Mandel, N., (2009), "The effects of thin and heavy media images on overweight and underweight consumers: Social comparison processes and behavioral implications”, Journal of Consumer Research, Vol. 36 No. 6, pp.930-949.

So, K. K. F. and King, C., (2010). "When experience matters": building and measuring hotel brand equity: The customers' perspective", International Journal of Contemporary Hospitality Management, Vol. 22 No. 5, pp.589-608.

Sotiriadis, M. D. and Van Zyl, C. (2013), "Electronic word-of-mouth and online reviews in tourism services: the use of twitter by tourists", Electronic Commerce Research, Vol. 13 No. 1, pp. 103-124.

Stayman, D. M., Alden, D. L. and Smith, K. H. (1992), "Some effects of schematic processing on consumer expectations and disconfirmation judgments",. Journal of Consumer Research, Vol. 19 No. 2, pp. 240-255. 
Stoycheff, E. (2016), "Under surveillance: Examining Facebook's spiral of silence effects in the wake of NSA internet monitoring", Journalism \& Mass Communication Quarterly, Vol. 93 No. 2, pp. 296-311.

Tesser, A. and Conlee, M. C. (1975), "Some effects of time and thought on attitude polarization”,. Journal of Personality and Social Psychology, Vol. 31 No. 2, pp. 262270.

Tsai, W.H.S. and Men, L.R., (2013), "Motivations and antecedents of consumer engagement with brand pages on social networking sites" Journal of Interactive Advertising, Vol. 13 No. 2, pp.76-87.

Tsang, A. S. and Prendergast, G. (2009), "Is a "star" worth a thousand words? The interplay between product-review texts and rating valences", European Journal of Marketing, Vol. 43 No. 11/12, pp.1269-1280.

Tsao, W. C., Hsieh, M. T., Shih, L. W. and Lin, T. M. (2015), "Compliance with eWOM: The influence of hotel reviews on booking intention from the perspective of consumer conformity", International Journal of Hospitality Management, Vol. 46, pp. 99-111.

Utz, S., (2015), "The function of self-disclosure on social network sites: Not only intimate, but also positive and entertaining self-disclosures increase the feeling of connection", Computers in Human Behavior, Vol. 45, pp.1-10.

Vogel, E. A., Rose, J. P., Okdie, B. M., Eckles, K., \& Franz, B. (2015), "Who compares and despairs? The effect of social comparison orientation on social media use and its outcomes", Personality and Individual Differences, Vol. 86, 249-256.

Wangenheim, F. and Bayón, T., (2004), “The effect of word of mouth on services switching: Measurement and moderating variables", European Journal of Marketing, Vol. 38 No. 9/10, pp.1173-1185.

Westbrook, R.A. and Oliver, R.L., (1991), "The dimensionality of consumption emotion patterns and consumer satisfaction", Journal of Consumer Research, Vol. 18 No. 1, pp.84-91.

Wetzer, I. M., Zeelenberg, M. and Pieters, R. (2007), ““'Never eat in that restaurant, I did!": Exploring why people engage in negative word - of - mouth communication” , Psychology \& Marketing, Vol.24 No. 8, pp. 661-680.

Xie, G.X. and Johnson, J.M.Q., (2015), "Examining the Third - Person Effect of Baseline Omission in Numerical Comparison: The Role of Consumer Persuasion Knowledge", Psychology \& Marketing, Vol. 32 No. 4, pp.438-449.

Xu, J. B. and Chan, A., (2010), "A conceptual framework of hotel experience and customerbased brand equity: Some research questions and implications", International Journal of Contemporary Hospitality Management, Vol. 22 No. 2, pp.174-193.

Xun, J. and Guo, B. (2017), “Twitter as customer's eWOM: an empirical study on their impact on firm financial performance", Internet Research, Vol. 27 No. 5, pp. 1014-1038.

Yang, Z., Jun, M. and Peterson, R. T. (2004), "Measuring customer perceived online service quality: scale development and managerial implications",. International Journal of Operations \& Production Management, Vol. 24 No. 11, pp. 1149-1174.

Yeh, Y. H. and Choi, S. M. (2011), "MINI-lovers, maxi-mouths: An investigation of antecedents to eWOM intention among brand community members", Journal of Marketing Communications, Vol.17 No. 3, pp. 145-162. 
Yen, C. L. A. and Tang, C. H. H. (2015), "Hotel attribute performance, eWOM motivations, and media choice", International Journal of Hospitality Management, Vol. 46, pp.7988.

Yu, X., Roy, S. K., Quazi, A., Nguyen, B. and Han, Y. (2017), "Internet entrepreneurship and "the sharing of information" in an Internet-of-Things context: The role of interactivity, stickiness, e-satisfaction and word-of-mouth in online SMEs' websites", Internet Research, Vol. 27 No.1, pp. 74-96.

Zerback, T. and Fawzi, N. (2017), "Can online exemplars trigger a spiral of silence? Examining the effects of exemplar opinions on perceptions of public opinion and speaking out”, New Media \& Society, Vol.19 No. 7, pp. 1034-1051. 


\section{Figures and Tables}

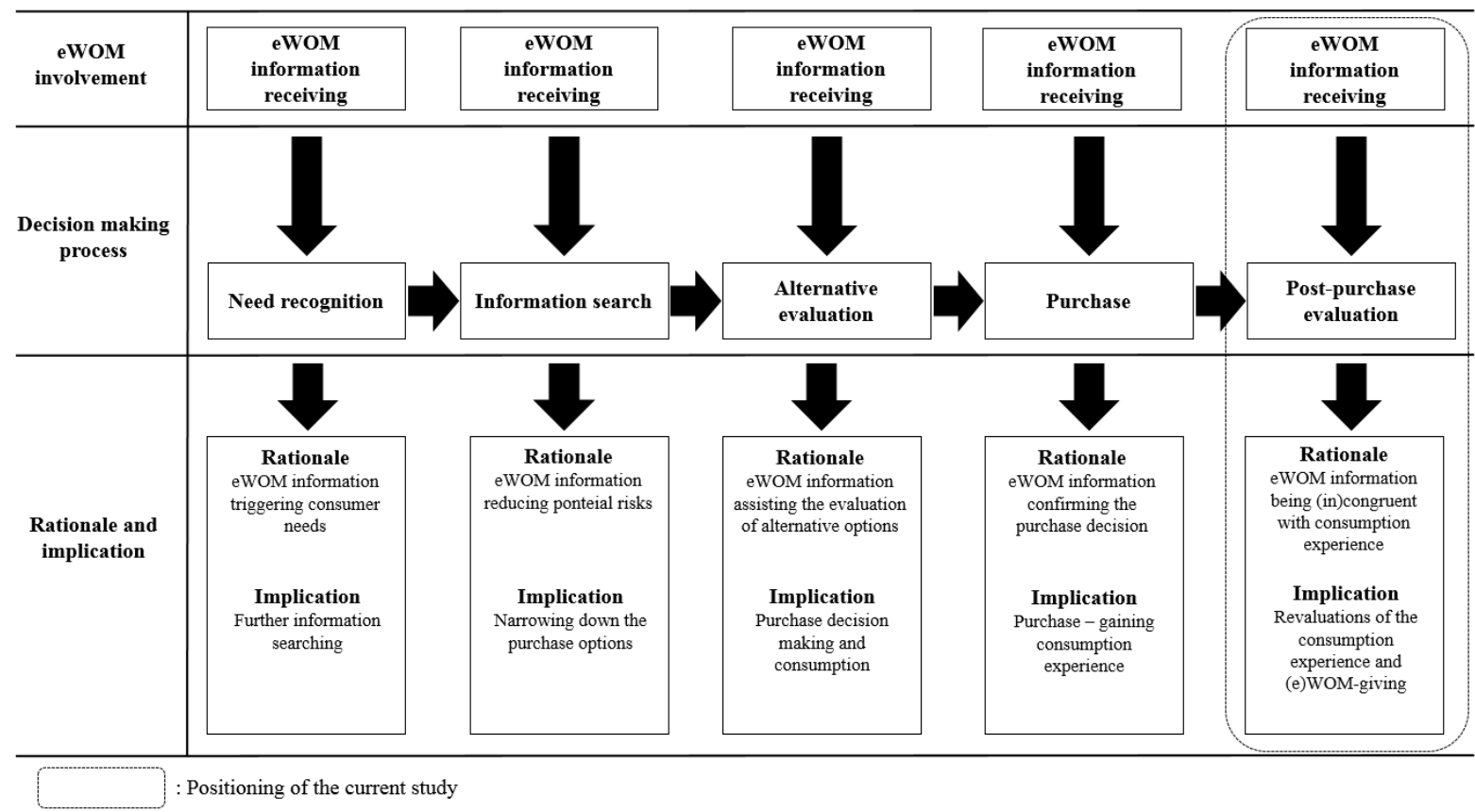

Figure 1: eWOM information receiving in consumer's decision-making process and research positioning 


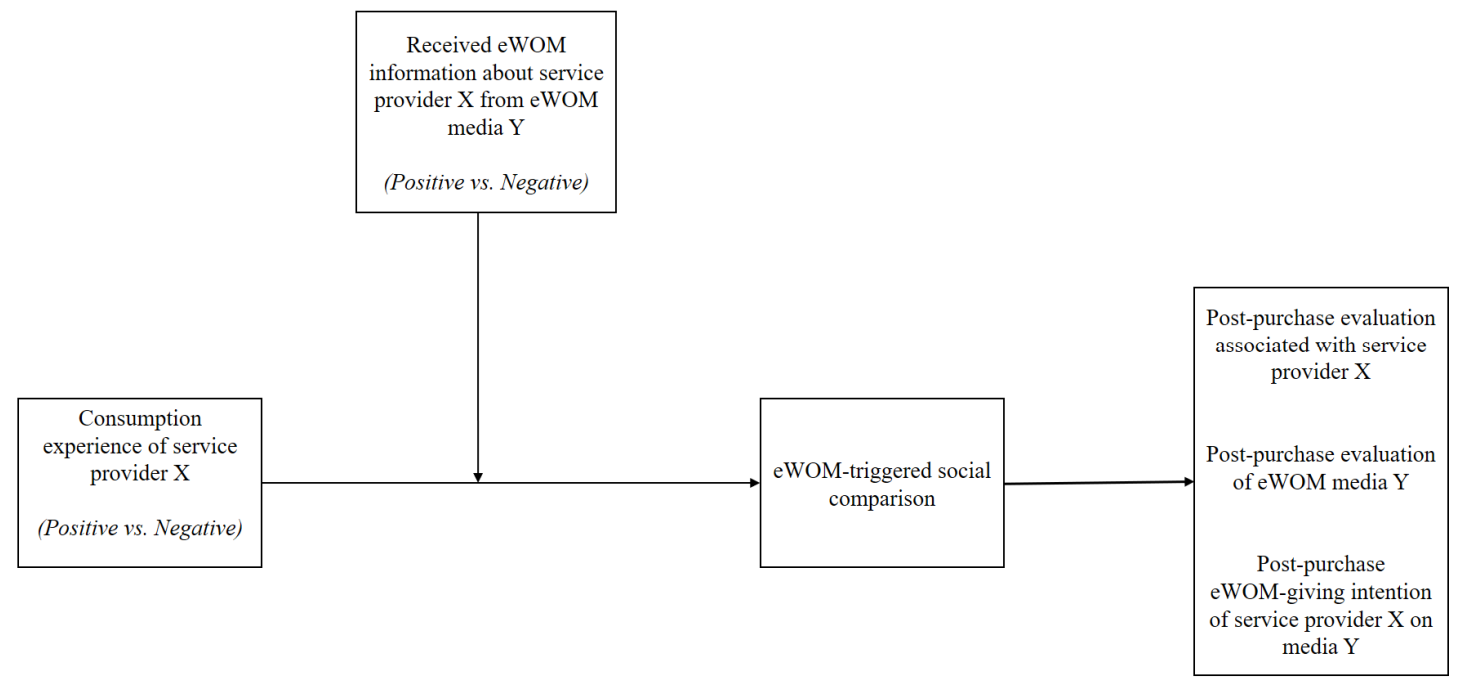

Figure 2: Research contextualisation 


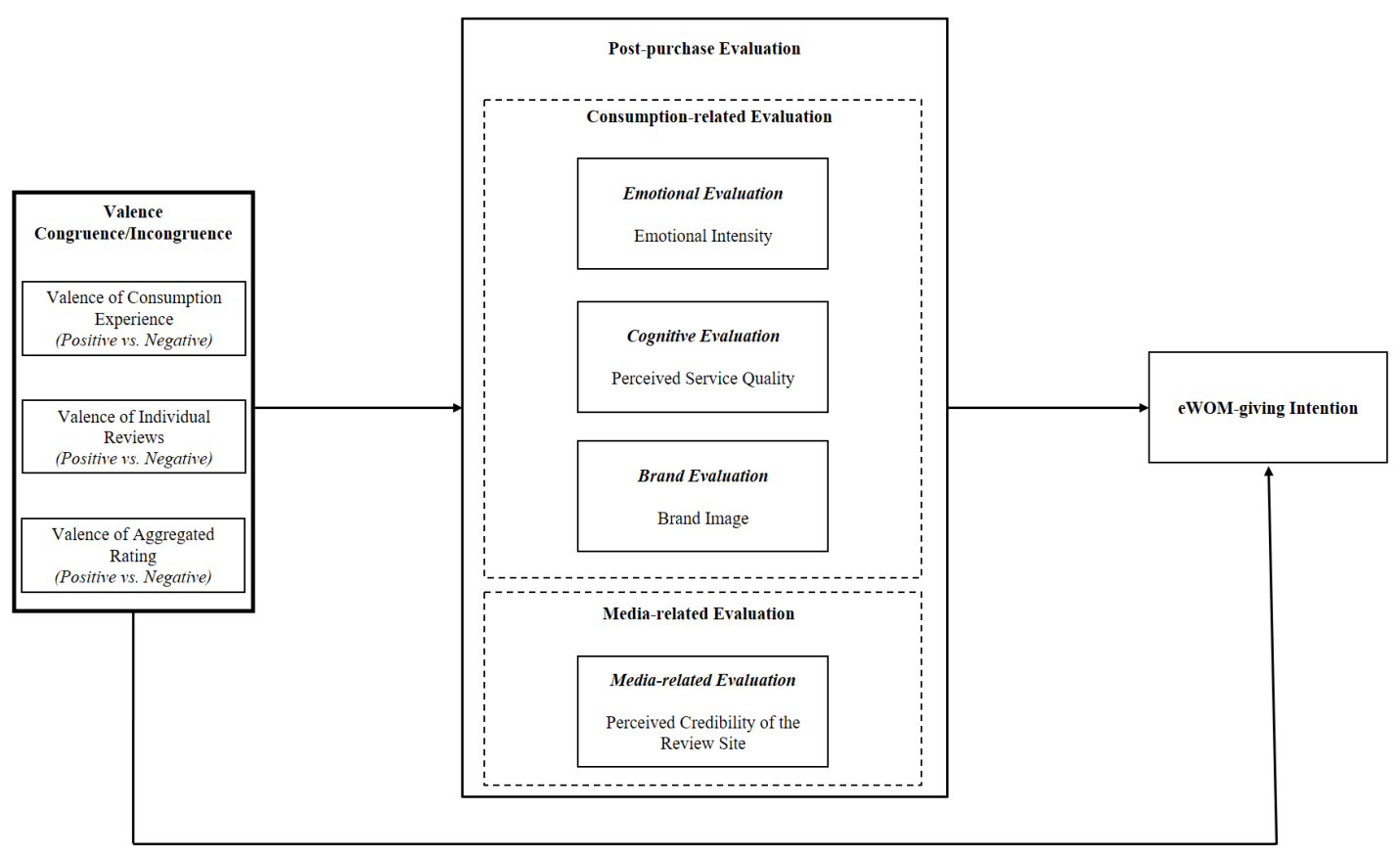

Figure 3: Conceptual framework 


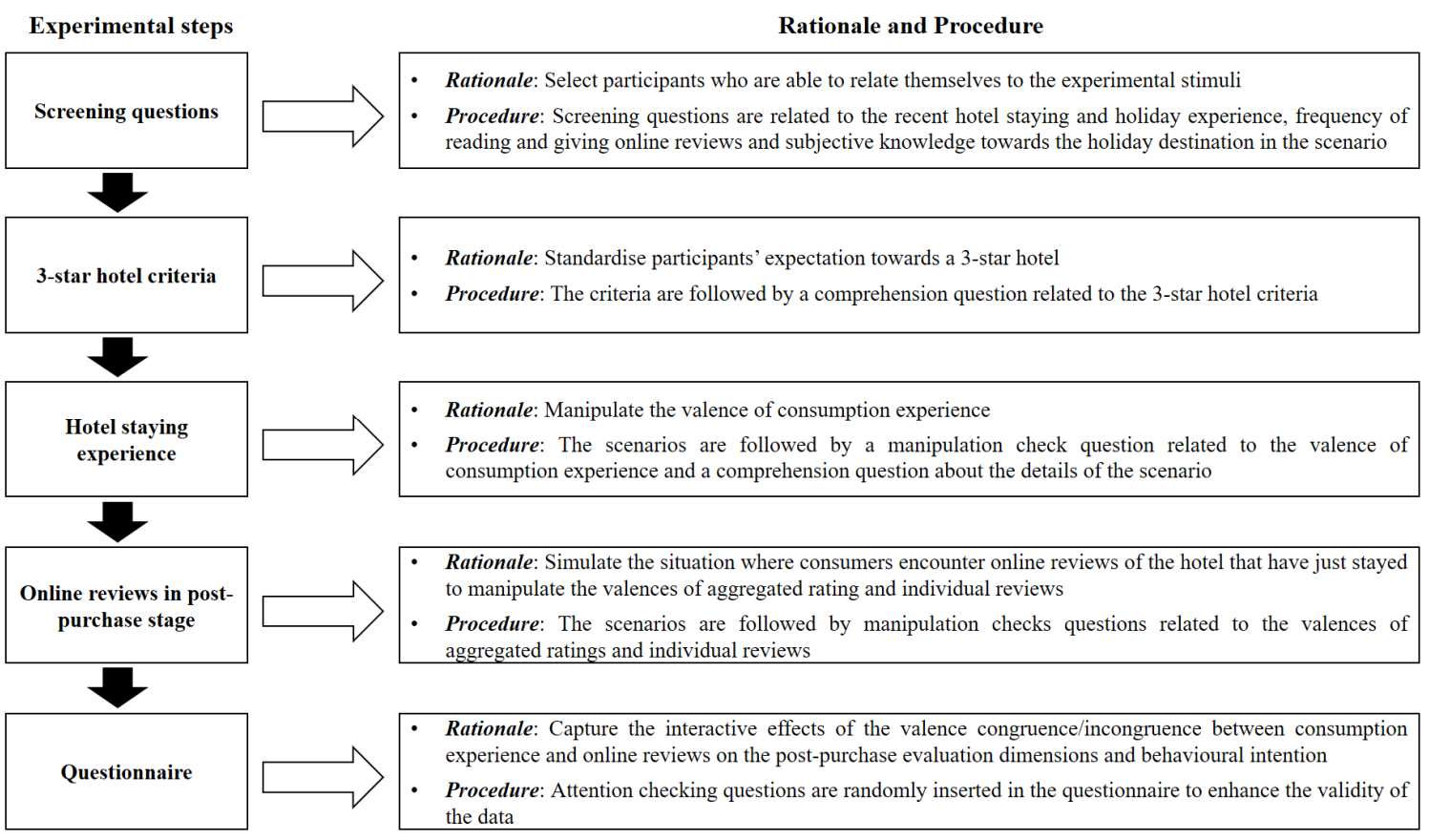

Figure 4: Experimental design and procedure 
Table 1: Information valence congruence/incongruence in eWOM studies

\begin{tabular}{|c|c|c|c|}
\hline Authors & Theory & $\begin{array}{c}\text { Valence } \\
\text { congruence/incongruence }\end{array}$ & Findings \\
\hline Chakravarty et al. (2010) & Persuasion theory & WOM vs. individual review & $\begin{array}{l}\text { When receiving incongruent WOM and online } \\
\text { reviews about a pre-release movie, frequent } \\
\text { moviegoers are more influenced by online } \\
\text { reviews while infrequent moviegoers are more } \\
\text { influenced by WOM. }\end{array}$ \\
\hline López-López and Parra (2016) & Signalling theory & $\begin{array}{l}\text { Aggregated rating vs. most } \\
\text { helpful individual review }\end{array}$ & $\begin{array}{l}\text { Incongruent valence between the most helpful } \\
\text { individual review and aggregated rating } \\
\text { influences the consumers' attitude towards the } \\
\text { product. }\end{array}$ \\
\hline Purnawirawan et al. (2012) & $\begin{array}{l}\text { Conformity tendency } \\
\text { theory }\end{array}$ & $\begin{array}{l}\text { First individual review vs. last } \\
\text { individual review }\end{array}$ & $\begin{array}{l}\text { Congruence between first and last reviews in a } \\
\text { list of online reviews leads to consumers' } \\
\text { impression bias in the same valence. }\end{array}$ \\
\hline Qiu et al. (2012) & Attribution theory & $\begin{array}{l}\text { Aggregated rating vs. individual } \\
\text { review }\end{array}$ & $\begin{array}{l}\text { Incongruent aggregated rating decreases review } \\
\text { credibility and diagnosticity for the positive } \\
\text { individual reviews but not for negative ones. }\end{array}$ \\
\hline Quaschning et al. (2014) & Dual-process theory & Multiple individual reviews & $\begin{array}{l}\text { Congruent valence of multiple reviews is } \\
\text { perceived as more helpful than any } \\
\text { incongruences, regardless of them being } \\
\text { positive or negative. }\end{array}$ \\
\hline Tsang and Predergast (2009) & Prospect theory & $\begin{array}{l}\text { Aggregated rating vs. individual } \\
\text { review }\end{array}$ & $\begin{array}{l}\text { Individual reviews have a stronger impact on } \\
\text { purchase intention, interest and trustworthiness } \\
\text { of the review. Congruent valence in general } \\
\text { leads to higher trustworthiness. }\end{array}$ \\
\hline
\end{tabular}


Table 2: Results of realism checks

\begin{tabular}{|lcccc|}
\hline \multicolumn{1}{|l}{ Scenario } & $\begin{array}{c}\text { Experimental } \\
\text { realism (mean) }\end{array}$ & t-Value & $\begin{array}{c}\text { Mundane } \\
\text { realism (mean) }\end{array}$ & t-Value \\
\hline $\begin{array}{l}\text { Positive CE } \\
\text { Positive AR x Positive IR } \\
(\mathrm{n}=20)\end{array}$ & 5.65 & $7.91^{*}$ & 5.70 & $8.23^{*}$ \\
$\begin{array}{l}\text { Positive AR x Negative IR } \\
(\mathrm{n}=27)\end{array}$ & 4.70 & $2.38^{*}$ & 5.48 & $6.00^{*}$ \\
$\begin{array}{l}\text { Negative AR x Positive IR } \\
(\mathrm{n}=26)\end{array}$ & 4.77 & $2.81^{*}$ & 5.31 & $4.64^{*}$ \\
$\begin{array}{l}\text { Negative AR x Negative IR } \\
(\mathrm{n}=20)\end{array}$ & 5.40 & $3.62^{*}$ & 6.10 & $14.65^{*}$ \\
$\begin{array}{l}\text { Negative CE } \\
\text { Positive AR x Positive IR } \\
(\mathrm{n}=26)\end{array}$ & 5.15 & $4.19^{*}$ & 5.31 & $4.94^{*}$ \\
$\begin{array}{l}\text { Positive AR x Negative IR } \\
(\mathrm{n}=21)\end{array}$ & 5.24 & $3.23^{*}$ & 5.19 & $3.41^{*}$ \\
$\begin{array}{l}\text { Negative AR x Positive IR } \\
(\mathrm{n}=20)\end{array}$ & 5.50 & $4.81^{*}$ & 5.70 & $5.67^{*}$ \\
$\begin{array}{l}\text { Negative AR x Negative IR } \\
(\mathrm{n}=20)\end{array}$ & 5.50 & $6.94^{*}$ & 5.90 & $10.72^{*}$ \\
\hline
\end{tabular}

Note: $*=\mathrm{t}$-values $>1.96 ; \mathrm{p}<.05$ (Field, 2009); $\mathrm{CE}=$ consumption experience; $\mathrm{AR}=$ aggregated rating; $\mathrm{IR}=$ individual reviews 
Table 3: Demographic distribution of the participants

\begin{tabular}{lrlr}
\hline \multicolumn{1}{c}{$n$} & & $n$ \\
\hline Age & & Education & \\
$18-20$ & 6 & Less than high school & 1 \\
$21-30$ & 108 & High school or equivalent & 30 \\
$31-40$ & 136 & Some college but no degree & 75 \\
$41-50$ & 59 & Associate degree & 45 \\
$51-60$ & 30 & Bachelor's degree & 139 \\
Above 60 & 8 & Graduate degree & 57 \\
& & & \\
Gender & & Employment & 255 \\
Female & 196 & Employed, full-time & 46 \\
Male & 151 & Employed, part-time & 40 \\
& & Unemployed & 3 \\
& & Retired & 3 \\
\hline
\end{tabular}


Table 4: Summary of experimental conditions

\begin{tabular}{|l|l|l|l|l|}
\hline & $\begin{array}{l}\text { Positive AR } \\
\text { Positive IR }\end{array}$ & $\begin{array}{l}\text { Positive AR } * \\
\text { Negative IR }\end{array}$ & $\begin{array}{l}\text { Negative AR } * \\
\text { Positive IR }\end{array}$ & $\begin{array}{l}\text { Negative AR } \\
\text { Negative IR }\end{array}$ \\
\hline Positive CE & A1 & B1 & C1 & D1 \\
\hline Negative CE & D2 & B2 & A2 \\
\hline Situation A & $\begin{array}{l}\text { When the valences of consumption experience, aggregated rating and } \\
\text { individual reviews are congruent. }\end{array}$ \\
\hline Situation B & $\begin{array}{l}\text { When the valences of consumption experience and aggregated rating } \\
\text { are congruent but opposite to the valence of individual reviews. }\end{array}$ \\
\hline Situation C & $\begin{array}{l}\text { When the valences of consumption experience and individual reviews } \\
\text { are congruent but opposite to the valence of aggregated rating. }\end{array}$ \\
\hline Situation D & $\begin{array}{l}\text { When the valences of aggregated rating and individual reviews are } \\
\text { congruent but opposite to the valence of consumption experience. }\end{array}$ \\
\hline
\end{tabular}




\section{Appendix 1: Examples of Experimental Scenarios}

\section{3* Hotel Standard in Scenarios}

Imagine that you are going to Orlando for a 5-day (4 nights) holiday with your partner (or best friend) during the summer time and staying in a hotel called Diamond Hotel that you booked about 6 weeks in advance. Diamond Hotel is recognized as a 3-star hotel on major hotel booking sites (e.g. Expedia, Hotels.com and Booking.com). You booked the hotel at the average price rate of $\$ \mathbf{1 0 0 / p e r}$ night for a standard room.

A brief of key standards for a 3-star hotel*

\section{Building/rooms}

Clean, hygienic, and all mechanisms and equipment are functional in a faultless condition.

\section{Furniture/equipment}

Toothbrush tumbler, soap or body wash, bath essence or shower gel, shampoo, cleansing tissue, and towels are available in the private bathroom. Double beds are a minimum of $1.80 \mathrm{~m} \times 1.90$ $\mathrm{m}$. Color TV with a remote control and telephone. Internet access in the public area or in the rooms.

\section{Services}

Daily room cleaning. Breakfast buffet or equivalent breakfast menu card that includes at least one hot beverage, a fruit juice, fruit or a fruit salad, a choice of bread and rolls with butter, jam, cold cuts, and cheese. Most offer 24-hour reception service.

* Adopted from the criteria for Hotelstars Union and Expedia Star Ratings (hotel class).

\section{Hotel Staying Experience}

\section{Positive Consumption Experience \\ Building/room}

The hotel looked magnificent from the outside. The whole building was neat and smelled fresh all the time. The hotel room was very bright, clean, and spacious.

\section{Furniture/equipment}

The wardrobe had a large built-in full-length mirror with separate luggage space in the closet. The bed was fairly big and comfortable. Different types of pillow were available for you to choose based on your preference. The sheet and duvet cover felt supple with attractively textured fabric. There were over $100 \mathrm{TV}$ channels available on the flat-screen TV in the room. 
The free Wi-Fi worked well. The bathroom was very clean, spacious, and was provided with branded toiletries.

\section{Service}

The room was cleaned daily. A wide range of tea and coffee with a selection of biscuits were supplemented daily. The breakfast buffet was served from 6:00 am to 11:00 am, offering a number of choices. Reception service was accessible $24 / 7$ by phone. The hotel staff were polite, friendly, and very helpful, and always had a smile on their face. The reception staff worked professionally and you were served almost immediately at check-in and check-out.

\section{Negative Consumption Experience}

Building/room

The hotel looked dirty and poorly maintained from the outside. The whole building seemed damp and there was a lot of mould visible. The hotel room felt pretty small and the carpet was covered with dust and hair.

\section{Furniture/equipment}

One corner of the built-in dressing mirror on the wardrobe was cracked. The bed size looked smaller than the standard double-bed size and the mattress was quite hard. The pillows that the hotel provided were too soft and the hotel claimed that they did not have alternative pillows after you asked about this. The texture of the sheet and duvet cover was quite rough and they had light-coloured stains on them. A small TV was installed in the room but did not function at all. The Wi-Fi was available in public areas, but not in the room. The hotel provided no toiletries in the bathroom.

\section{Service}

The room was cleaned on the first two days. On the second two days, the room was only cleaned if required. Only a couple of tea bags and instant coffee sachets were available in the room and these were not supplemented after being consumed. The breakfast buffet was served from 7:00 am to 10:00 am with a very limited choice. A call to reception was not answered on the third night. A request to change the room was rejected out of hand. The reception staff worked rather inefficiently and check-in and check-out took about 15 minutes. 


\section{Appendix 2: The scales}

Emotional Intensity (López-López et al., 2014)

After experiencing the scenario, I feel a sense of...

Anger (negative)/enjoyment (positive)

Sadness (negative)/pleasantness (positive)

Irritation (negative)/euphoria (positive)

Disappointment (negative)/fun (positive)

Frustration (negative)/entertainment (positive)

Resentment (negative)/happiness (positive)

Indignation (negative)/enthusiasm (positive)

Disgust (negative)/fascination (positive)

Service Quality (Brady and Cronin Jr., 2001; Liu and Jang, 2009)

The service of Diamond Hotel is dependable and consistent.

I would say that Diamond Hotel provides superior service.

I believe Diamond Hotel offers excellent service.

Brand Image (Chiang and Jang, 2007)

Overall, I think this hotel brand is:

Unfavourable to Favourable

Unattractive to Attractive

Worthless to Valuable

Bad Reputation to Good Reputation

eWOM Giving Intention (Leung et al., 2015)

My willingness of writing a review about this staying experience on TripAdvisor is very high.

The probability that I would consider writing a review about this hotel staying experience on TripAdvisor is very high.

The likelihood of writing a review about this hotel staying experience to others on TripAdvisor is very high.

Perceived Credibility of the Review Site (Cheung et al., 2009)

I think the information on TripAdvisor in the scenario is factual. 
I think the information on TripAdvisor in the scenario is accurate.

I think the information on TripAdvisor in the scenario is credible.

Valence of Consumption Experience (Duprez et al., 2015)

Using the rating scale below, please rate how positive/negative the scenario was for you (strongly negative/strongly positive, 10-point Likert scale).

Perceived Valence of Aggregated Rating (Antheunis et al., 2010)

How would you think about the aggregated rating of Diamond Hotel on TripAdvisor left by other consumers? (Strongly negative/strongly positive, 7-point Likert scale)

Perceived Valence of Individual Reviews (Antheunis et al., 2010)

How would you think about the individual reviews of Diamond Hotel on TripAdvisor left by other consumers? (Strongly negative/strongly positive, 7-point Likert scale) 


\section{Appendix 3: Statistical Figures}

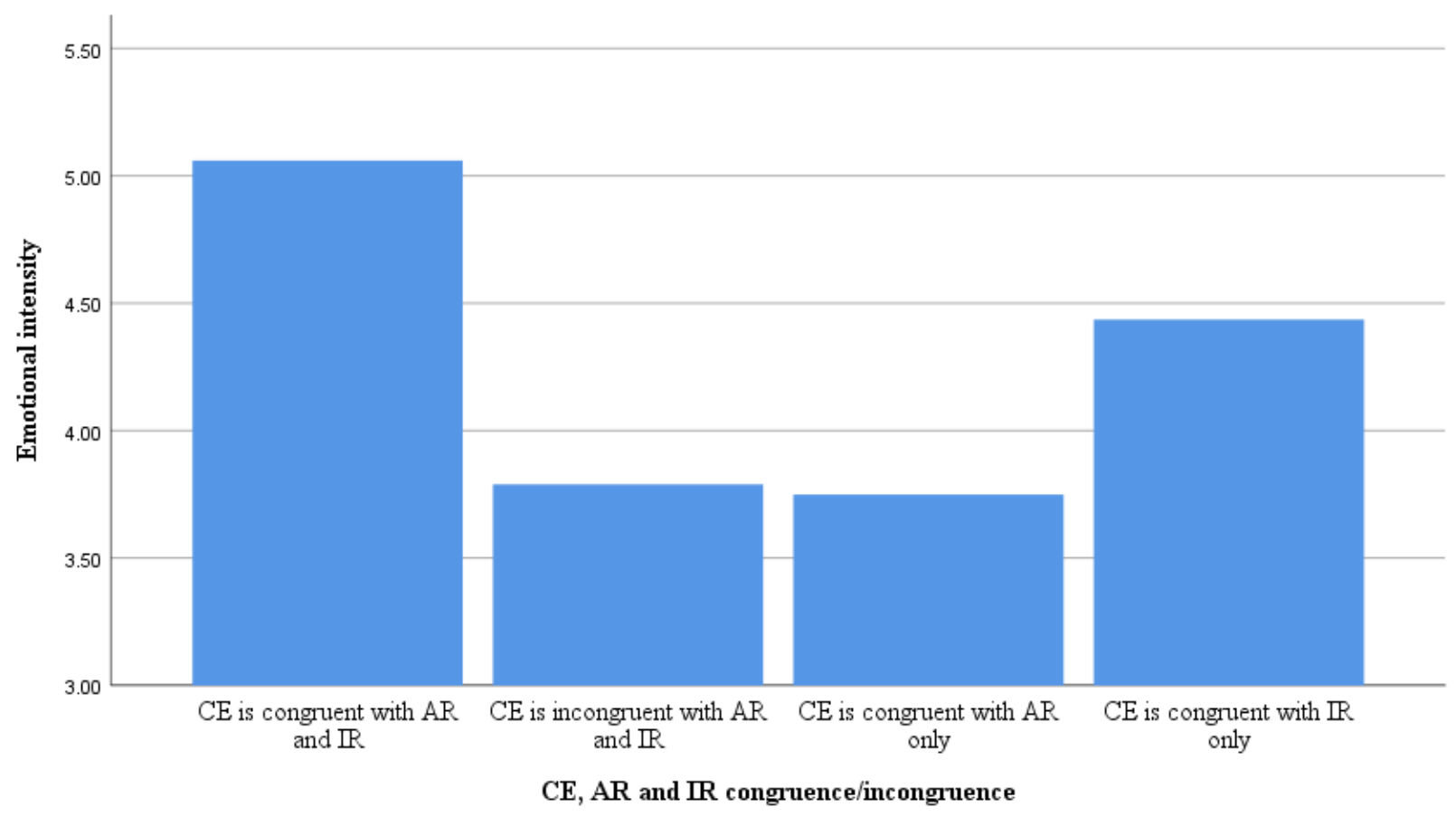

Figure 5: The effects of CE, AR and IR congruence/incongruence on emotional intensity

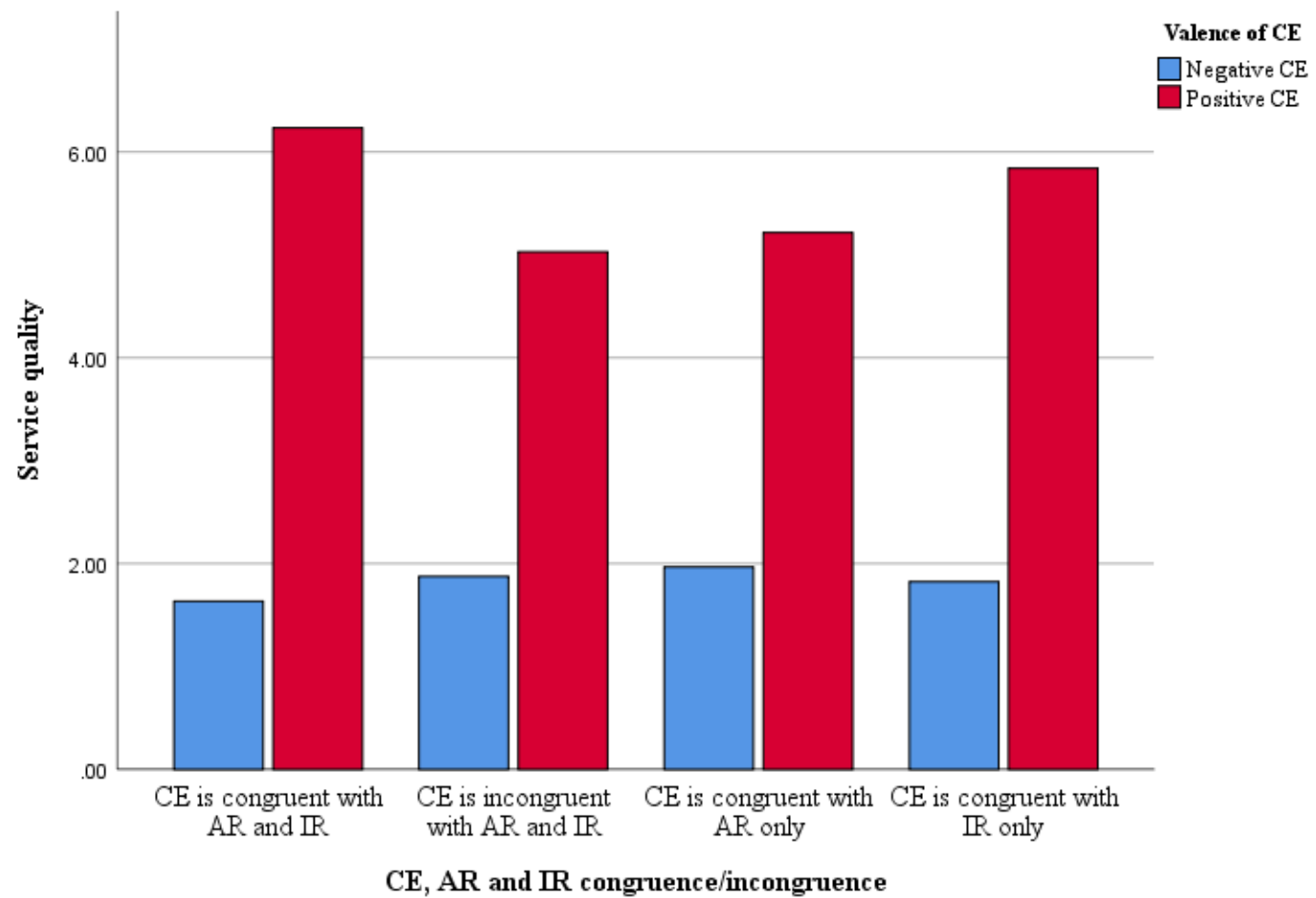

Figure 6: The effects of CE, AR and IR congruence/incongruence on service quality (clustered by the valence of $C E$ ) 


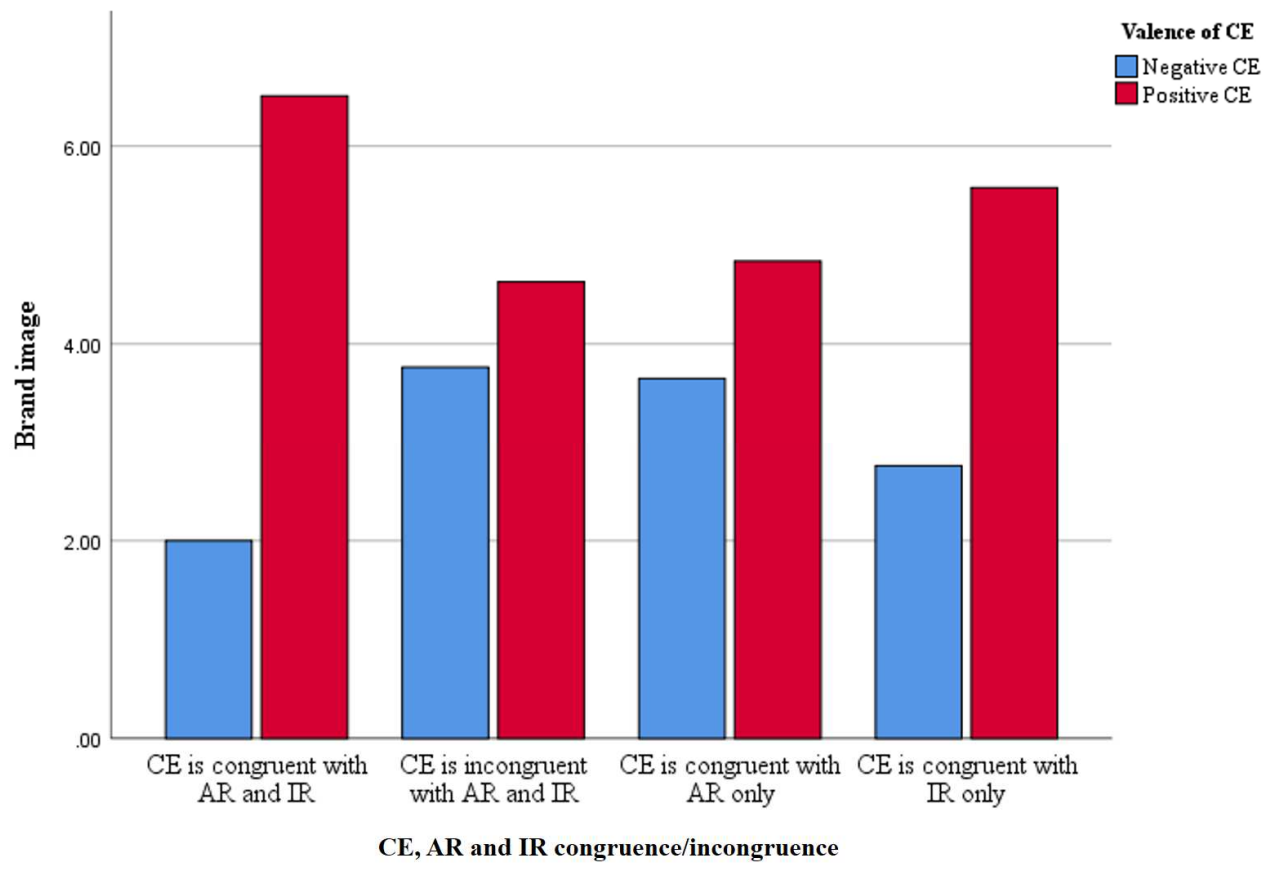

Figure 7: The effects of CE, AR and IR congruence/incongruence on brand image (clustered by the valence of $C E$ )

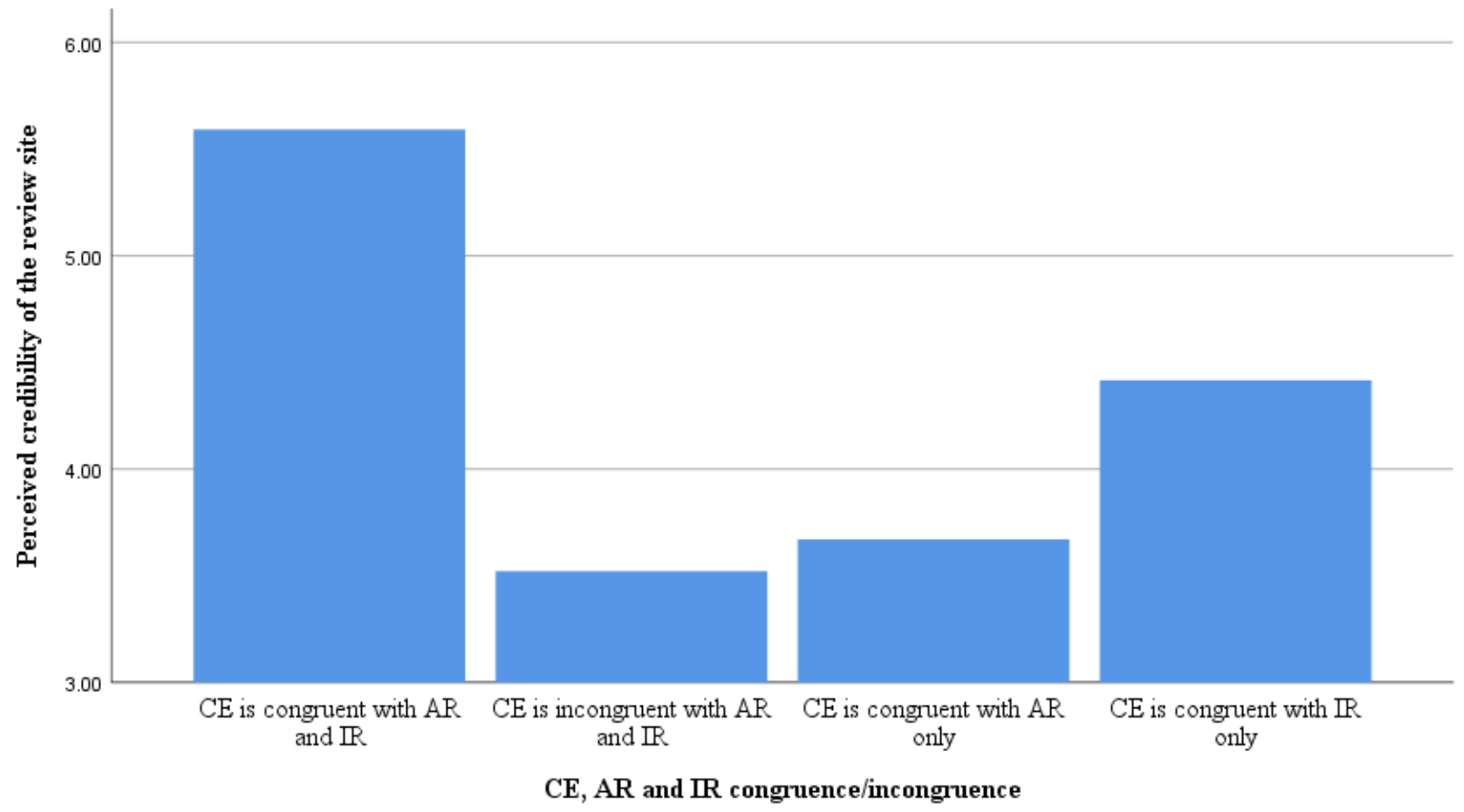

Figure 8: The effects of CE, AR and IR congruence/incongruence on perceived credibility of the review site 


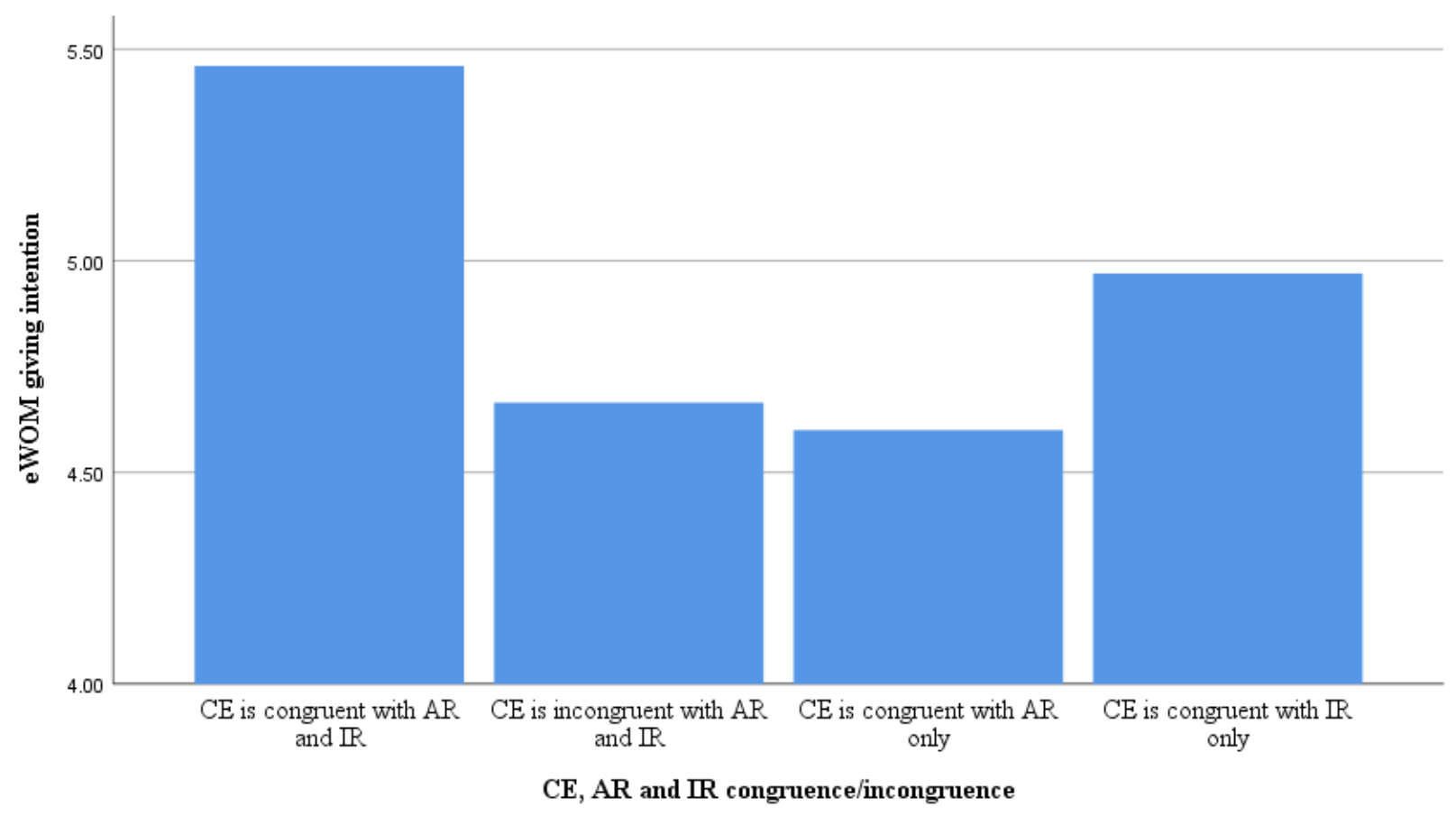

Figure 9: The effects of CE, AR and IR congruence/incongruence on eWOM-giving intention 